Portland State University

PDXScholar

$1-15-2021$

\title{
Developing an Archaeologically Literate Citizenry Through Public Archaeology: Assessing Archaeology Websites
}

Lisa Marie Catto

Portland State University

Follow this and additional works at: https://pdxscholar.library.pdx.edu/open_access_etds

Part of the Anthropology Commons

Let us know how access to this document benefits you.

Recommended Citation

Catto, Lisa Marie, "Developing an Archaeologically Literate Citizenry Through Public Archaeology: Assessing Archaeology Websites" (2021). Dissertations and Theses. Paper 5645.

https://doi.org/10.15760/etd.7517

This Thesis is brought to you for free and open access. It has been accepted for inclusion in Dissertations and Theses by an authorized administrator of PDXScholar. Please contact us if we can make this document more accessible: pdxscholar@pdx.edu. 
Developing an Archaeologically Literate Citizenry through Public Archaeology:

Assessing Archaeology Websites

by

Lisa Marie Catto

A thesis submitted in partial fulfillment of the requirements for the degree of

\section{Master of Science}

in Anthropology

Thesis Committee:

Virginia L. Butler, Chair

Shelby L. Anderson

Kathi A. Ketcheson

Portland State University

2020 


\begin{abstract}
Assessment has been a growing focus of public archaeology in recent years, however, most assessment has focused on in-person activities with little on digital public archaeology. With the pervasive popularity of digital media, such as websites, among global public audiences and the popularity of websites as a communication tool for archaeologists, it is critical that archaeologists focus on evaluating websites to make this public-facing communications tool as effective as possible. My thesis addressed this gap in assessment by using Qualitative Content Analysis (QCA) to assess the messaging on the most popular archaeology websites, defined based on Google ranking. My specific goals were to determine if QCA was an effective tool for such assessment and to learn what messages are both prominent and lacking on these websites.

To develop an assessment approach using QCA, I began by selecting Franklin and Moe's (2012) five themes as a content framework to evaluate archaeology messages on websites. The themes are: Access to Archaeology, Archaeological Content, Fundamental Concepts of Archaeology, Stewardship and Preservation, and Uses of Archaeology. These themes represent commonly held ideas archaeologists have suggested the public should know about. According to Franklin and Moe, understanding these themes will create an archaeologically literate public.

I selected the 15 most popular websites for the study by searching "archaeology" in Google and choosing the first 15 organizations that met established criteria. I categorized the websites by organizational focus: higher education, media outlet, professional organization, and publicly accessible space. My sampling approach was to use the "top navigation" of the websites for consistency. I prepared the records so I had a static version of each webpage to code, imported them into ATLAS.ti, and then systematically coded the webpages for website organization, Franklin and Moe theme, and webpage element (e.g., body text, photo, headline). I also re-coded the first 10
\end{abstract}


webpages to assess intracoder reliability (which was relatively high). I analyzed a total of 103 pages, which took approximately 27 hours (including preparing the records and coding the pages).

A total of 1,151 distinct messages were tallied from the 15 webpages.

Fundamental Concepts of Archaeology and Archaeological Content dominated the messages with frequencies of 437 and 304, respectively. Stewardship and Preservation and Uses of Archaeology were rarely represented, with frequencies of 96 and 95, respectively. Seven of the 15 websites studied lacked references to one or both of these themes completely. Given the importance of Stewardship and Uses (which establishes the relevance of archaeology to our everyday lives) to the growth and development of our discipline, and the web's importance for the public to learn about archaeology, my results highlight much needed website re-tooling.

Overall, QCA proved to be a useful tool for assessing archaeology websites. It allowed me to understand the extent and presence of the Franklin and Moe themes by providing a systematic way to evaluate all webpage content. I also determined the themes were a good framework for QCA, as all content I wanted to code on the webpages could be assigned to those themes. Procedurally, the sampling methodology I used produced a robust sample of websites and a consistent sample of webpages among them, my record creation process produced usable static documents for coding, and ATLAS.ti software enabled effective coding and analysis for this project.

My thesis shows that archaeologists have to do better in communicating messages about conserving the archaeological record and demonstrating how archaeology can be used to address contemporary problems such as racism, social justice, and immigration. Websites will continue to grow as an important way for archaeologists to engage the public. Given their prominence and the importance of assessment in general, website assessment clearly deserves more scholarship. Not only do we need to critically evaluate 
what we are communicating through websites (and social media platforms), we need methods for conducting such assessment. Supporting this work could involve analysis of ways other fields use QCA as well as other website assessment options to identify the most effective approaches for archaeologists. 


\section{Dedication}

To my parents, Steve and Georgene, for their unconditional love and unwavering support. Thank you for always believing in me and teaching me you can do anything if you try. 


\section{Acknowledgements}

This project would not have been possible without the support and guidance of my advisor and mentor, Dr. Virginia Butler. Her steady enthusiasm and passion for public archaeology inspired me to keep going. I am grateful for getting to embark on this journey with her and for her dedication to helping me succeed in this program. I am also very grateful for the support and input of Dr. Shelby Anderson and Dr. Kathi Ketcheson, who generously served on my thesis committee and offered valuable insight and expertise to this this project.

I would also like to thank the PSU anthropology faculty for creating a welcoming environment to students. I truly enjoyed learning from each of them in and out of the classroom. And to my fellow PSU graduate students who have been wonderful friends and colleagues. I am thankful for everything I learned from them and for their support through this process.

Thank you to Dr. Robin Smith and the anthropology faculty at Western Oregon University for helping me develop a love for this field and for encouraging me to pursue graduate school.

For the public archaeologists having serious and thoughtful conversations about our field, I appreciate the work they are doing. I appreciate them for sharing their work and finding ways to engage the public in archaeology. Special thank you to Dr. Kate Ellenberger, a friend who is making amazing contributions in public archaeology and whose insights I always appreciate.

Lastly, I would like to extend my deep gratitude to my family, friends, and colleagues who have supported me through this long journey. From starting grad school two weeks after my last chemo appointment, through many hours of long drives to class, and motivating me when things were difficult, I appreciate them all so much. 


\section{Table of Contents}

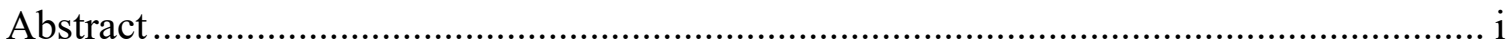

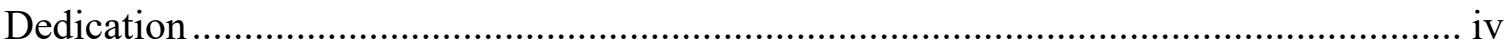

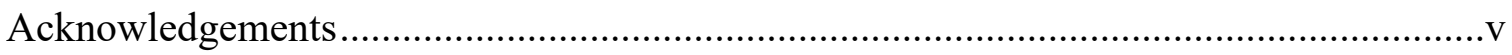

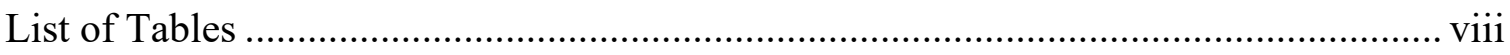

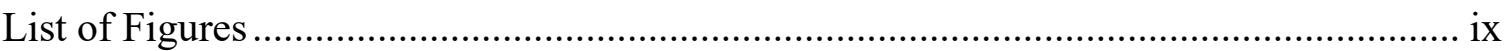

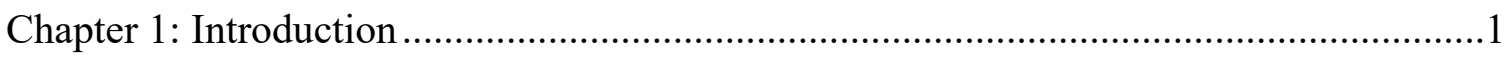

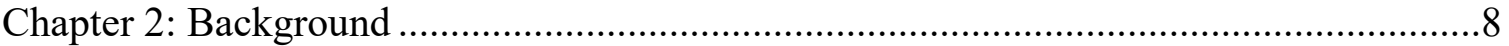

Assessment in Education ........................................................................ 8

Assessment in Public Archaeology .................................................................... 9

Digital Public Archaeology and Websites ...........................................................15

Website Best Practices and Assessment .................................................................. 17

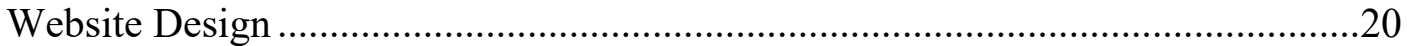

Qualitative Content Analysis ............................................................................22

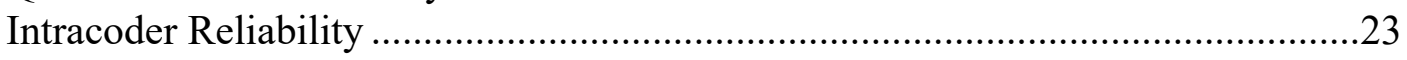

Computer-Assisted Qualitative Data Analysis .....................................................24

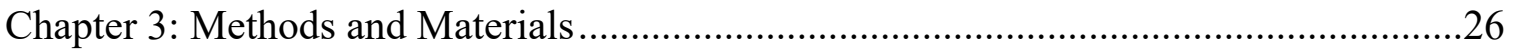

Sampling Websites for Analysis .......................................................................26

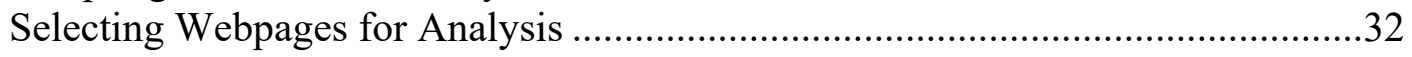

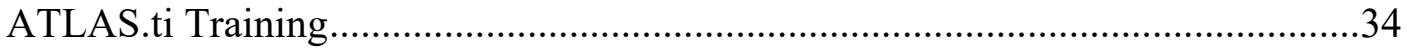

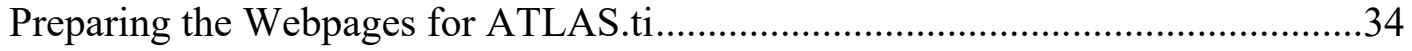

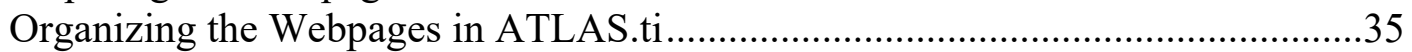

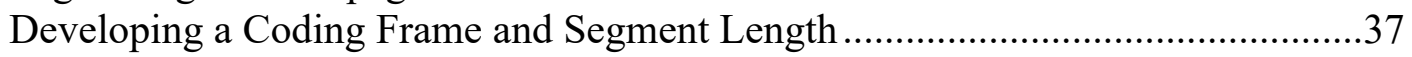

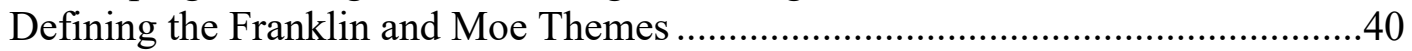

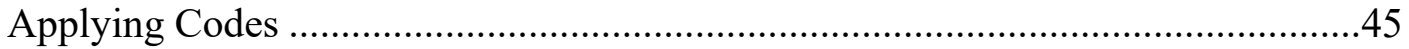

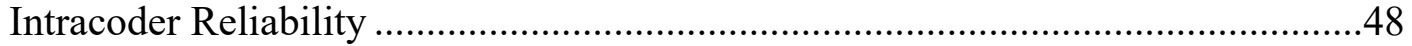

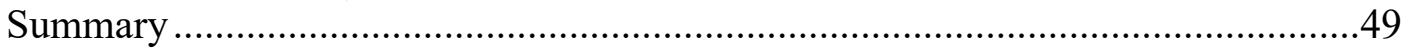

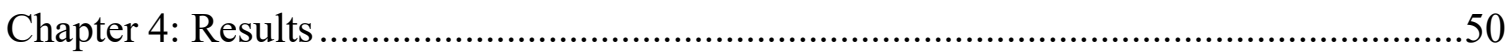

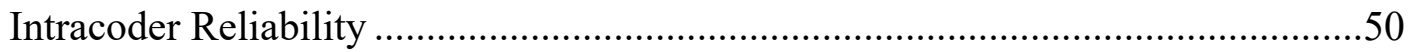

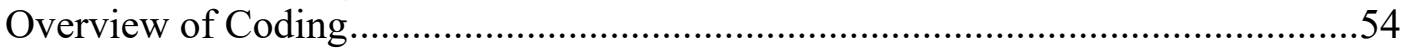

To What Extent are the Franklin \& Moe Themes Used Within Archaeology

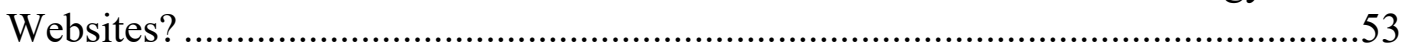

What Content did the Webpages Focus On? ......................................................61

Did Word Count Impact the Quantity of Archaeology Messages? .........................63

What are Good Examples of Each Franklin and Moe Theme? ...............................64 


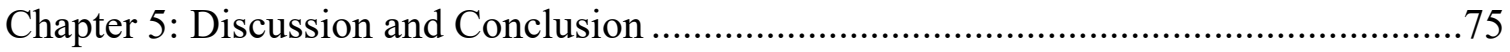

Was QCA a Good Assessment Tool? ............................................................. 75

What Messages are Missing from the Most Popular Archaeology Websites? ........77

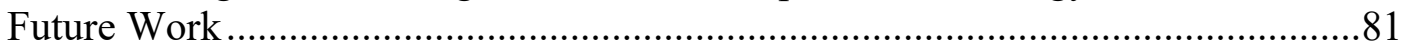

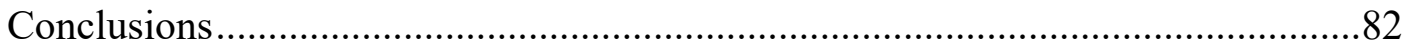

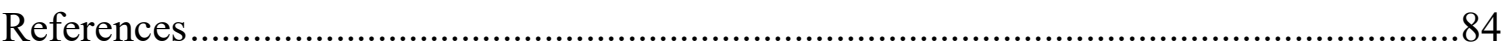

Appendix A: Table of Code Frequency of Franklin and Moe Codes and Webpage Element Codes by Webpage 


\section{List of Tables}

Table 1. List of Archaeological Themes Provided by Franklin and Moe (2012), Which they Suggest will Contribute to an Archaeologically Literate Citizenry ..........................6

Table 2. List of Websites Included in Thesis Project Analysis .....................................28

Table 3. A Comparison of Coding Results Between First and Second Coding Passes on

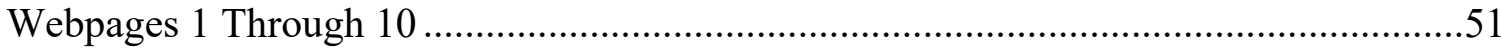

Table 4. The Frequency of Each Theme Overall and Per Website ................................55

Table 5. The Frequency of Each Theme by Website Category .....................................60

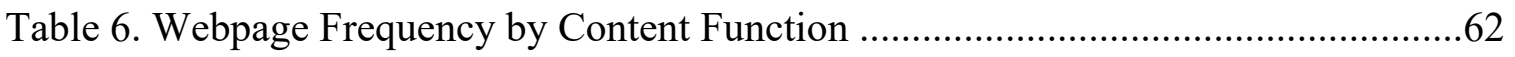

Table 7. Franklin and Moe themes by Webpage Content Function ...............................63

Table 8: Traits of the Franklin and Moe (2012) Themes and Possible Ways to Demonstrate Them in Digital Media 


\section{List of Figures}

Figures 1a-c. Screenshots from the first page of Google search results to demonstrate the websites and webpages both included and not included in the research

Figure 2. Screenshot from the Archaeology Magazine home webpage showing the top navigation.

Figure 3: A screenshot of the Random.org list randomizer used to assign numbers to each webpage

Figure 4: A screenshot of the three code groups and individual codes within ATLAS.ti.39

Figure 5: Example of Access from the American Museum of Natural History's

"archaeology" webpage

Figure 6: Example of Content from The Archaeology Channel's "home” webpage

Figure 7: Example of Fundamental Concepts from a photo on the Archaeological Institute of America's "home" webpage.

Figure 8: Example of Fundamental Concepts from the Society for American Archaeology's "what is archaeology" webpage

Figure 9: Example of Stewardship theme from Mount Vernon's “archaeology” webpage showing the entire top navigation on that website. The "preservation" navigation link was a coded segment

Figure 10: Example of Uses from Carleton College's archaeology department "home" webpage

Figures 11a-b: A screenshot from Archaeology Magazine in ATLAS.ti, demonstrating the connection between a quotation and codes I applied $47-48$

Figure 12: A collection of human remains from unknown site, University of Oxford webpage. On the first pass, coded as Content; on the second pass as Fundamental Concepts.

Figure 13: A scatterplot comparing the total webpages per website against the total number of codes per website.

Figure 14: A stacked bar chart showing the frequency of Franklin and Moe themes illustrated by website

Figure 15: A stacked bar chart showing the percent of codes per theme by website 
Figure 16: A scatterplot comparing frequency of body text codes to word count of each webpage

Figure 17: Carleton College's "Home" webpage listed degree programs that are supported through archaeological study (Uses)... 66

Figure 18: Mount Vernon's "Archaeology home" webpage had a sentence that connected archaeology to a social justice issue (Uses)..... .66

Figure 19: Mount Vernon's "Preservation" webpage included an interactive opportunity to engage to take a quiz (Stewardship)

Figure 20: The Archaeological Institute of America's "Site Preservation" webpage had an infographic about site preservation (Stewardship)

Figure 21: An image from Mount Vernon's "The Estate" webpage inviting people to participate in a virtual tour (Access)

Figure 22: Archaeology Magazine's "Home" webpage includes this graphic advertisement for Crow Canyon Archaeological Center (Access)

Figure 23: An example from Mount Vernon's “Archaeology Home” webpage that uses a strong image, text and call to action (Content)

Figure 24: City of Boston's "Home" webpage uses video and a call to action with image and text (Content)

Figure 25: University of Exeter's "Fieldwork" webpage used video to show fieldwork (Fundamental Concepts).

Figure 26: City of Boston's "Home" webpage had information about how archaeology excavations are conducted and shows a collection of artifacts (Fundamental Concepts).74 


\section{Chapter 1: Introduction}

"Unless archaeologists find ways to make their research increasingly relevant to the modern world, the modern world will find itself increasingly capable of getting along without archaeologists" (Fritz and Plog 1970:412).

Through this thesis project, I conducted a Qualitative Content Analysis (QCA) on a series of archaeology websites to understand how archaeology is being communicated through this important medium. More broadly, my thesis research contributes to a wider effort to incorporate assessment practices into public archaeology work. While there is a growing focus on assessment within public archaeology, there has been little in digital public archaeology. Without assessing effectiveness of websites and being intentional about both their construction and content creation, archaeologists are in effect communicating without strategy or purpose (Richardson 2013). As with most digital public archaeology assessment, there has been little scholarship on what makes an archaeology website "good." Assessing archaeology websites could be a first step toward creating an archaeologically literate public by understanding the information that archaeologists are distributing.

Public archaeology is a subfield of archaeology focused on increasing awareness of ways the public benefits from archaeology, through theoretical scholarship and applied work (Matsuda and Okamura 2011, Richardson and Almansa-Sanchez 2015, Society for American Archaeology 2016, Wilson 2015). While a key goal of public archaeology is to ensure long-term preservation of cultural resources, most practitioners see that the scope reaches well beyond such matters. The complex dynamics linking the profession and the public are illustrated with Franklin and Moe's statement: public archaeology can be "with the public, for the public, of the public, or archaeology of public resources" (2012:569; 
emphasis in original). For example, public archaeology can be collaborative, such as community-based projects that grow organically from local concerns (Atalay 2012). It can involve advocacy and supporting protection of significant sites (Little and Shackel 2014). And given that much archaeology, especially in the United States, is funded from taxpayer dollars, all such archaeology is in a sense "public." Public archaeology is embedded in numerous areas including cultural resource management (CRM), Indigenous rights, politics and policy, formal interpretation of the past, in museums or in signage for example, heritage tourism, education and curriculum, archaeological ethics, law, popular culture and media, and more (Little 2012, Matsuda and Okamura 2011, Richardson and Almansa-Sanchez 2015).

Public archaeology provides innumerable benefits for the public that are far more complex and richer than satisfying a curiosity about the past. Archaeology can address legal and political issues; provide evidence for policy changes and intellectual property rights issues (Atalay 2012); aid peacebuilding in conflict zones through cultural heritage (Little and Shackel 2014); promote harmonious living in a multicultural world by helping people both understand and embrace diversity (Little 2002:13); and support community cohesion, often through demonstrating a shared historical bond (Atalay 2012, McManamon 2002:32). There are numerous civic engagement and social justice benefits (Little and Shackel 2007, Shackel 2007), including fighting against racism through dispelling racist ideas based on biological misinterpretations (Crist 2002); providing credible accounts of things that happened in the past, which give a platform to marginalized voices and legitimize experiences left out of historical records (Crist 2002, Lipe 2002); and helping reconstruct heritage lost through colonization and conquest 
(McManamon 2002:34). There are also educational benefits to the public, like a better understanding of local history (Atalay 2012); using archaeology to meet educational standards, such as those in the United States that require understanding of Indigenous societies (Little 2002:12); and helping individuals develop critical thinking skills that can be used to sift through information thrown at us daily from all directions (Little 2002:11, McManamon 2002:36). Archaeology supports and informs other disciplines of interest to the public: environmental issues, understanding disease, and waste management (Crist 2002, Hardesty and Little 2009, Little 2002, Rathje 2002); and forensic science uses archaeological methods to investigate individual crimes and massacres (Crist 2002). Lastly, we cannot discount the public benefit that is the joy of discovering something about the past (Little 2002) and the sense of pride and protection one feels when helping to preserve sacred and fragile sites (Society for American Archaeology 2016). Public archaeology is also important to archaeologists as it is a key element of many legal standards and requirements (Hardesty and Little 2009), and if archaeologists can help the public to understand the implications of archaeological research, the public may demand more financial support for the discipline (Atalay 2012).

Public archaeology is conducted through a wide range of mediums, from inperson interactions (e.g., site visits, lectures, museum tours, community collaborative excavations), to traditional media (e.g. books, magazine articles, journal articles, broadcast interviews), to digital technology (e.g., websites, mobile apps, social media platforms, podcasts). The latter have opened a wide range of free-to-low cost options for archaeologists to share their work with the public. Of the digital technologies now available to archaeologists, websites are the most popular medium (Childs 2002, Goskar 
2012, Limp 2011, Lock 2006, McDavid 2004, Richardson 2013, Walker 2014a). A novice can easily create a website for free through the wide array of tools available. Inperson public archaeology programs are often relatively inaccessible, whereas websites can be accessed from any location with an internet connection. Archaeology websites have been created for projects, professional organizations, government agencies, nonprofits, media outlets, tribes, and more. A Google search of the terms "archaeology" and “archeology" produced approximately 149,800,000 combined results out of the more than 1.743 billion websites worldwide (as of January 2020) (Internet Live Stats 2020), which demonstrates the pervasive presence of archaeology online. This importance has grown since the global pandemic of COVID-19 began (as of March 2020 in the U.S.) and has emphasized the need for strong digital communication. More than half of Americans said the internet has been essential during the COVID-19 outbreak (Pew Research Center 2020). This increased reliance on digital engagement will likely be the new normal.

Along with the developing interest in and support for public archaeology, as seen in the increasing number of symposia at conferences (e.g., Society for American Archaeology, European Association of Archaeologists, World Archaeological Congress), creation of journals devoted to the subfield (Public Archaeology, Advances in Archaeological Practice, Internet Archaeology, Journal of Community Archaeology and Heritage), and edited volumes (e.g., Skeates et al. 2012, Stone 2015), there has been a growing concern for assessment of public archaeology practices (e.g., Bartoy 2012, Franklin and Moe 2012, King 2016). How much of an impact are public archaeology practices having on public attitudes? Are our efforts increasing the "archaeological literacy" of the public? King suggested there is little discussion around best practices and 
assessment of effectiveness and how archaeologists and educators must "spend fruitless time reinventing the wheel" because there is no unified movement forward that can be built upon (2016:416). She argued the discipline lacks a unified vision of what archaeologists want to convey to the public, project goals are often unspecified, and the absence of assessment is a core issue with public education. When there is assessment, King said it is often informal, like raw numbers of participants in a program. As Franklin and Moe (2012) explain, in developing assessment processes we need a shared view of goals, namely what we want the public "to know," or to understand about the human past. They suggest that once we settle on the traits an archaeologically literate citizenry should possess, then, borrowing from education and social science research methods, we can devise methods of gauging whether the public has gained these insights. To begin this process, Franklin and Moe (2012) have proposed that an archaeologically literate citizen understand the importance of, and ideas behind, five essential themes: 1) stewardship and preservation of archaeological sites, 2) fundamental concepts of archaeology, 3) uses of archaeology (e.g., using archaeology to teach critical thinking skills), 4) access to archaeology (e.g., partnering with communities on archaeology projects), and 5) archaeological content (e.g., results of specific projects) (Table 1). In many ways, these themes are sufficiently general and using them as guides would not force any redirection of action - they simply formalize what most public archaeology practices would consider standard directions for their work. Their main value could be their use as a basis for assessing the extent these themes are incorporated into public archaeology today. 
Table 1: List of Archaeological Themes Provided by Franklin and Moe (2012), Which They Suggest Will Contribute to an Archaeologically Literate Citizenry

\begin{tabular}{lcl}
\hline \multicolumn{1}{c}{ Theme } & Abbreviation & \multicolumn{1}{c}{ Description } \\
\hline $\begin{array}{l}\text { Stewardship and } \\
\text { Preservation of } \\
\text { Archaeological Sites }\end{array}$ & $\begin{array}{c}\text { Stewardship } \\
\text { (Steward.) }\end{array}$ & $\begin{array}{l}\text { What is lost through site destruction from } \\
\text { looting and poor planning; the value of context }\end{array}$ \\
$\begin{array}{l}\text { Fundamental } \\
\text { Concepts of }\end{array}$ & $\begin{array}{c}\text { Fundamental } \\
\text { Concepts } \\
\text { Archaeology }\end{array}$ & $\begin{array}{l}\text { How we know what we know (e.g. field and } \\
\text { lab methods, dating techniques) }\end{array}$ \\
$\begin{array}{l}\text { Uses of Archaeology }) \\
\text { Uses }\end{array}$ & $\begin{array}{l}\text { Teaching various subjects and ideas through } \\
\text { archaeology and archaeological evidence (e.g. } \\
\text { biology through faunal remains, social justice } \\
\text { through Indigenous archaeology) }\end{array}$ \\
$\begin{array}{l}\text { Access to } \\
\text { Archaeology }\end{array}$ & Access & $\begin{array}{l}\text { Multivocality, engaging audiences in } \\
\text { archaeological discourse }\end{array}$ \\
Archaeological & Content & $\begin{array}{l}\text { Archaeological data, results, interpretation } \\
\text { about past people }\end{array}$ \\
\hline
\end{tabular}

In terms of assessing the content of archaeology websites, I propose that the Franklin and Moe themes are a good starting point in the absence of anything else widely accepted across the discipline. The concepts within these five themes are ideals archaeologists have extensively advocated for in peer-reviewed literature, conference sessions, museum visits and site tours, and in the classroom. Perhaps, if the discipline adopts universal ideals like Franklin and Moe's themes, those seeking to advance public archaeology assessment could build methodologies from them. Accepting such themes 
and explicitly stating so would give archaeologists a common language and framework from which to do public archaeology work and assessment.

My thesis project responds to this call for a more intentional public archaeology, which seeks to create a more archaeologically literate citizen. I contributed to this process by evaluating whether Qualitative Content Analysis (QCA) was an effective tool to assess a sample of archaeology-focused websites. As noted above, websites are a key way the public engages with archaeology. In particular, I used QCA to assess the extent Franklin and Moe's themes were addressed in the websites. I conducted a Qualitative Content Analysis of $\sim 15$ archaeology websites ( $\sim 100$ webpages) using ATLAS.ti software to code the presence, extent and use of the five themes on the websites I selected. I found specific examples of how each theme was used and showcased those to demonstrate how the themes were used well or could be integrated more to illustrate possibilities for future website creators to consider.

This thesis is organized into five chapters. In Chapter 2, I discuss the background of digital public archaeology and websites, Qualitative Content Analysis, and computerassisted qualitative data analysis. Chapter 3 details my methods for selecting a sample of archaeology websites, how I prepared the documents for coding in ATLAS.ti, development of the coding scheme and how I decided to apply which codes. In Chapter 4, I present the results of my intracoder reliability testing, the extent and presence of the Franklin and Moe themes, and a look at a possible connection between archaeology messages and amount of text on a webpage. In Chapter 5, I discuss those results, highlight specific ways websites support the Franklin and Moe themes, which could be incorporated in future website design, and suggest directions for future work. 


\section{Chapter 2: Background}

\section{Assessment in Education}

Before exploring the role assessment has played in public archaeology, it is important to define assessment and better understand the origin from which public archaeology began using these concepts. Assessment has a long history in education, particularly in terms of standardized testing in schools after WW1, and is an important

part of the educational process (Wiliam 2010). Assessment in education can measure success of schools and programs, student achievement and can measure against elements such as specific criterion or the work of others (Wiliam 2010).

Formative assessment and summative assessment are the two types of assessment most commonly found in education, and subsequently public archaeology. Formative assessment is assessing during learning with the goal of collecting feedback in order to modify and improve the educational activities (Black and Wiliam 1998, Dixson and Worrell 2016). Formative assessment focuses on what is working and what needs to be improved through activities like homework, self-evaluations, quizzes, and observations. Conversely, summative assessment is focused on evaluating learning outcomes through understanding whether a student grasps the material and if the student is prepared to move on to the next level (Dixson and Worrell 2016, Zohre 2018). Examples of summative assessment activities in education include projects, portfolios, papers, and exams. Formative assessment can be spontaneous or planned. For example, during a classroom activity, a teacher could spontaneously ask the students how they are enjoying 
an activity. Or using a public archaeology example, a museum docent could ask a visiting group what exhibit was their favorite. Summative assessment activities are typically more formal than formative assessment; and can have "higher stakes," affecting whether an educational practice or curriculum continues to be used (Dixson and Worrell 2016). Both formative and summative assessment activities can help education researchers gauge whether educational practices are meeting project goals. My thesis project, which analyzes previously created websites, is an example of summative assessment.

An important component of assessment in education is the use of learning outcomes or creating learning goals that can be used to guide curriculum development (Ebbeck et. al. 2014). Ebbeck et. al. suggest learning outcomes can measure myriad traits, such as linking the major domains of children's development to specific learning achievements to help educators and caregivers understand where a child may be on a development spectrum connected to specific milestones. Learning outcomes can also extend beyond education. My project treats the five Franklin and Moe themes as learning outcomes or goals. In effect, the authors suggest that if the public learns the principles and ideas embodied in the five themes, the public will be archaeologically literate. As discussed below, I will assess the extent these learning goals are addressed in archaeological websites using QCA.

\section{Assessment in Public Archaeology}

Though education science has inspired some assessment in public archaeology, assessment is not yet a standard practice across the field (Apaydin 2016, Bollwerk 2015, King 2016). To characterize the state of assessment practices, I carried out a literature 
review for the period between 2010 and 2019 and identified nine articles that incorporate assessment related to archaeological site visits, museums, the classroom, and social media.

Much of the public archaeology assessment scholarship is connected to specific archaeological sites through educational activities, site visits, and tours. I will detail two examples: one at the Çatalhöyük site in Turkey and the other a collaborative project between archaeologists and the Ho-Chunk Nation in Wisconsin. Çatalhöyük is one of the world's longest-running archaeological education programs (established in 2002). Apaydin (2016) wanted to understand the long-term impact of the Çatalhöyük education program so they measured whether visitors saw an increase in their knowledge and awareness of archaeology and heritage. Apaydin surveyed Turkish teenagers and young adults who both had and had not visited the site as children within the past seven-to-10 years. Apaydin learned the education program had positively influenced archaeological understanding in the local community as those who had visited the site showed more archaeological knowledge and site knowledge, as well as stronger heritage perceptions than those who had not visited the site. The survey proved to be a useful tool in achieving Apaydin's goals.

While Apaydin used surveys with the recipients of educational programs, Reetz and Quackenbush (2016) used them to assess a partnership between archaeologists and the Ho-Chunk Nation. The educational program was developed to introduce tribal youth to archaeology and geology by creating a hands-on and place-based learning experience. Reetz and Quackenbush surveyed tribal staff and archaeologists involved in the project; only three completed surveys were returned to the investigators. Though a low sample 
size, they gained useful qualitative information that demonstrated a strong partnership between the tribal staff and archaeologists; and the research gathered specific ideas of how to improve the program in future iterations. Surveying as an assessment method provided Apaydin, Reetz, and Quackenbush the opportunity to reflect on ways to strengthen their programs in meaningful and tangible ways.

As an example of museum-based assessment, Thum and Troche (2016) curated a project at Brown University, called "Uncovering Ancient Egypt," where broken and unprovenienced ancient Egyptian artifacts were used as tools for hands-on education to learn about modern investigative technology. Their two primary educational goals were to identify universal teaching strategies to employ broken and unprovenienced museum artifacts and help visitors feel more connected to archaeology. Thum and Troche conducted a survey on two occasions and asked docents to record questions from sixth graders in a specific museum gallery. They received 43 survey responses and felt the results demonstrated the participants' interest in archaeology and an increased understanding of the discipline. The informal docent-acquired anecdotes produced a list of questions that demonstrated the students' interest in learning more about archaeology and the museum, as well as strengthening connections between the museum and local schools. Ultimately, Thum and Troche found these two assessment tools beneficial toward incorporating "visitor feedback as a reflective practice" (2016:547).

Several public archaeology projects using formal classroom experiences have incorporated assessment. Two examples address Common Core Standards in Rhode Island as well as a long-term project both in-and-out of the classroom in Kentucky. Ducady et. al. (2016) assessed the effectiveness of a program called "Think Like an 
Archaeologist," which was developed to enhance social studies curriculum and develop a variety of skills important to the Common Core Standards (e.g., critical thinking). They issued the same questionnaire to middle school students before and after they participated in the program (170 took the pre-program test and 193 took the post-program test). Ducady et. al. found that the program led to a demonstrated increase of archaeological knowledge among the students, however, the students did not show an increased understanding of academic vocabulary. The paired questionnaire approach allowed Ducady et. al. to understand specific knowledge gained and skills developed among children who had archaeology curriculum with field trips.

In the second classroom case study, Henderson and Levstik (2016) conducted a Kentucky Archaeological Survey (KAS) project to study using archaeology to help students understand the past by incorporating archaeology into the curriculum of local elementary classrooms (74 student participants) through an intensive archaeology classroom unit and field trips. The assessment included a written survey of students at the midpoint of the unit, classrooms activities, student discussions, interviews with students at conclusion of the unit, and coding of each data set (e.g., written assignments, discussion notes). Two-to-three years later, Henderson and Levstik interviewed 29 of the original participants to understand how much information had been retained and found that the students recalled and spoke fondly of the hands-on activities (specifically those involving holding artifacts) but struggled with skills around making inferences. This project helped the authors identify specific activities and concepts that were confusing to the students in order to strengthen the curriculum for future children. Also, the results demonstrated how powerful artifacts are to learning experiences and the lasting impact 
they can have on children. The projects by Henderson and Levstik and Ducady et. al. demonstrate how a multi-pronged assessment can produce robust results.

Very few examples of assessment at archaeology fairs have been published. Thomas and Anderson Langlitz (2016) assessed archaeology fairs to better understand effectiveness of the fair model, the role of such events, and strategies to organize effective fairs. Their methodology included a survey of 92 fair organizers from around the world and a "fair trivia checkpoint" survey for visitors at an AIA (Archaeological Institute of America) fair. With the organizer survey, they discovered three universal goals: introducing archaeology basics, introducing the community to local archaeological resources, and demonstrating diversity of topics. The "fair trivia checkpoint" survey helped Thomas and Anderson Langlitz re-evaluate the AIA's goals for its fair and activities. As with the other types of public archaeology programs discussed so far, surveys continue to be a popular tool in archaeology assessment.

There is also some scholarship addressing assessment in digital spaces. I will share two examples involving museum Facebook pages; one from the Museum of London and one from Conjunto Arquelógico de Carmona in Spain. Kelpšienė (2019) used the Museum of London Archaeology's Facebook page analytics (e.g., likes, shares, comments) to evaluate how its followers reacted to various forms of content. They also conducted a qualitative content analysis on the posts categorized into five content themes: fieldwork news, archaeological finds, events and exhibitions, digital projects, and job/Ph.D. applications. Kelpšienė did not see a strong correlation between the content theme and audience engagement, nor did they determine that small and original content campaigns had a positive impact on what the users considered to be valuable. Kelpšiene 
suggested that it is important for organizations to be more intentional about their social media presence. This study emphasizes the importance of setting goals for digital content.

A second example of digital assessment is by Rodríguez Temiño and González Acuña (2014), who used the Conjunto Arquelógico de Carmona's Facebook page to try to rekindle interest in the museum among locals and better understand the demographics of residents interested in the museum. They tracked the museum's followers' demographics before and after implementing a digital campaign. Rodríguez Temiño and González Acuña learned that most of the locals who engaged with the posts did so on a more surface level (e.g., liking instead of commenting or sharing a post). They also learned the primary value in their Facebook page was to communicate with those already familiar with the museum rather than attract new visitors, which is important knowledge to aid in content creation. Also, similar to Kelpšienè, Rodríguez Temiño and González Acuña advocated for all communication to be goal-oriented.

The final example of assessment in digital media came from Moyer (2015), who assessed whether the Urban Archaeology Corps' (UAC) non-traditional field school program, in Washington, D.C., met the goals of increasing support of stewardship among youth and awareness/interest in the National Park Service (NPS) as a career path. Moyer surveyed the youth participants at multiple intervals, conducted a demographics survey, and interviewed them half-way through the program. They learned that participants left the UAC program with more knowledge about archaeology, increased enthusiasm about parks and heritage, and increased interest in NPS opportunities for the future. By conducting interviews during the program, Moyer was able to make adjustments to the second half of the program based on feedback. They found that the combination of the 
surveys and interviews provided strong data collection to help them improve the cocreation process with participants and the program overall.

\section{Digital Public Archaeology and Websites}

Digital technologies have revolutionized the way archaeological information is shared and accessed. Websites, in particular, provide a low-cost and easily accessible communication tool (Richardson 2013, Walker 2014b). Traditional public archaeology approaches (e.g., lectures and site visits) are narrower in their reach but allow archaeologists to adapt their messaging to the audience through in-person interactions. Websites can reach a much broader audience, but archaeologists lose the flexibility to customize their messaging and the experience becomes less controlled and more impersonal. This is a challenge because in public archaeology there are a lot of potential “publics," such as the community around a site, Indigenous communities, government officials and political leaders, funding organizations, and more. It is difficult to focus on specific publics through websites because there is no restriction to who accesses a site, and often, archaeologists want websites to be of interest to everyone, so they are developed with a broad purpose in mind.

There are many benefits for using websites as a tool in digital public archaeology. Websites provide an easily accessible venue for website creators to add their perspectives on subjects. This multivocal inclusiveness is a goal of many public archaeologists, particularly to include marginalized and Indigenous voices (Richardson 2014). Cocreation is an important focus in archaeology today and websites are a good media for such work (Bollwerk 2015). There are engagement models, like the Digital Engagement 
Spectrum (Bollwerk 2015), that can aid archaeologists in more effectively engaging with their audiences in collaborative ways. Websites also offer an alternative avenue and support the sharing of archaeological information in numerous forms (e.g., text, images, video) and on any topic more than traditional publishing allows. Also, websites are a flexible communication medium that can be easily changed to suit the needs of an archaeologist or archaeological project, which is a flexibility that traditional publishing avenues generally lack.

While the benefits are vast, there are numerous pitfalls in using websites as a tool for digital public archaeology. There is no universal quality control on websites, which means anyone with a computer and internet access can easily create one and post information without peer review (Richardson 2014). On websites with legitimate archaeological information, a level of digital literacy is expected of website visitors to be able to sift through archaeological information and determine its accuracy (Richardson 2014). Websites, in effect, even the playing field by granting equal access to pseudoarchaeologists sharing inaccurate information through providing the same opportunities to create and publish websites. Search engines like Google praise popularity over quality, which may promote pseudoarchaeological websites over more trusted sources if those websites are visited more frequently than those with scientifically sound information (Richardson 2014). Also, information can be collected, altered, and released back into the world and it is not always possible to track when that happens (Bollwerk 2015).

Another drawback of using websites for archaeology is the chance of intentionally or accidentally sharing protected archaeological information because websites are 
dynamic and easier to produce than formal publications. A website creator can move too quickly and possibly post information without first considering proprietary information or intellectual property issues, or even share information via insecure locations through websites (Styliaras 2015).

Creating and managing websites also requires a skillset not taught in archaeology academic programs; the ability to write in plain language to reach a broad audience is critical for websites. Also, digital technologies have changed how people expect to receive their information, often in a more on-demand and fast-paced fashion, which places different expectations on how archaeologists communicate. This can be complicated by the digital divide, which seems to be more apparent during the COVID19 pandemic as schools struggle to ensure their students have access to necessary technology (Lederman 2020).

\section{Website Best Practices and Assessment}

In spite of the importance of websites, there is little academic scholarship on best practices and models for assessing websites. Most scholarship I found was in the disciplines of communications, community health, and education. Specific to website assessment literature, a majority of the articles focused on methods involving users and their response to the websites as opposed to the intent and goals of website creators.

For context to understand website assessment scholarship, I sought out articles that examined trends among website assessment. Sun et. al. (2016) reviewed 103 published articles on website assessment in hospitality and tourism from 2000-15 and 
found the articles did not "discuss in detail the implications of website evaluation" (Sun et. al. 2016:355). Of the 103 articles, 74 of them focused on the consumers' perspective as opposed to the perspective of the suppliers/organization. This is a theme common in website assessment articles in other industries as well with many of the evaluation methodologies involving user surveys and interviews. I was unable to find any website assessment articles focused on whether websites are communicating what the discipline or website creator intends. Overall, the website assessment articles are cursory when discussing their methods, which makes it difficult for others to replicate their methods.

Much of the scholarship around website assessment is focused on how the enduser interacts with websites and their experiences. Colombo et. al. (2016) studied an Italian website created to provide people with multiple sclerosis (MS) and their families with evidence-based information. Specifically, Colombo et. al. sought to understand how successful the website was in helping the public on topics related to MS, so they created a 29-question survey about the website's ease of language, contents, navigation, and usefulness and were able to get 433 responses (276 from people with MS, 68 family members, and 89 others). Their project, Integrating and Deriving Evidence, Experiences and Preferences (IN-DEEP), involved three phases to the website development: understand, develop, and evaluate. In the "understand" phase, they conducted focus groups and created an online forum to learn how people with MS and their family members access and use MS treatment information as the early development stage for the website (2016: 2). The "develop" phase involved creating and testing a template that was used to summarize MS treatments and research and they held meetings with various stakeholders and conducted a pilot test. The final phase, "evaluate," involved 
understanding if the website met the needs of people with MS, which led to revisions of the website and uploading the final version online. Overall, their evaluation focused on the perspectives of the website's end users.

Other scholarship used Google Analytics and statistical data available to website managers as primary assessment sources. Jeong et. al. (2019) studied a website eMentalHealth.ca, created to help Canadians learn about mental health, screen for common issues, and seek services. Jeong et. al. used Google Analytics and selfadministered surveys to understand how the site was used and the level of visitor satisfaction with the website. They studied website traffic data from 2017 and found that there were 651,107 users with 1.97 million page views. Google Analytics provided data on the geographic areas with the most website visitors. Of the visitors, 370 completed the survey with $93 \%$ of those stating they were satisfied with the website. The access to Google Analytics helped Jeong et. al. better understand where their heavy users were located so they could consider targeted outreach to those regions, while the surveys helped them to identify technical and design issues.

The degree to which a website is usable by its target audience(s), is a critical component to a successful website. Kaur et. al. (2016) studied the usability of 10 university websites using two automated tools available online: Site Analyzer and Qualidator. Both of these tools assess search engine optimization (SEO), performance (e.g., load times), design, content, and accessibility. These tools allowed Kaur et. al. to identify specific issues among the websites, particularly in terms of elements critical to all websites, regardless of subject matter (e.g., accessibility, performance), but they were 
not designed to identify "quality of content" or how well users understood the information conveyed.

There are few recent peer-reviewed studies that address the quality of website content. Sowter et. al. (2016), assessed the quality and content of 39 websites about herbal remedies for menopausal symptoms. The websites they analyzed were commercial, government, or non-profit organizations. They identified the websites to study by collecting recommended search terms from health service providers and female participants. They used two tools for their project: DISCERN addressed readability of the website content and SMOG assessed information coverage. DISCERN is a healthcare tool that "assesses the quality of written information on health-related treatment choices" (Sowter et. al. 2016:17). SMOG (Simple Measure of Gobbledygook) assesses readability of written content by estimating how many years of education the reader would need to understand the content through examining polysyllabic words and sentence length of up to 30 sentences from a document (also primarily used for health-related content). Readability is an important factor to consider when creating website content, but these tools, as with those used by Kaur et. al. (2016), cannot be used to assess how well website content performs in conveying specific messages and such tools ignore photos and other visual forms of content.

\section{Website Design}

Previous scholarship (Redish 2012, Yannacopoulos et al. 2014) in website best practices suggests that a "good" website requires meeting standards in layout, design, accessibility, navigation, and content. Arguably the most challenging component of 
website creation is content. Writing is a difficult task for any communication vehicle, not just websites (Connah 2010, Fagan 2010, Zimmerman 2003). A key strategy to writing engaging content is through plain writing so it is understood by people of diverse backgrounds and education levels. The goal of "plain writing" is to communicate in a way that a wide audience can understand what you are saying without them needing specialized knowledge (PLAIN n.d.). If websites are filled with lengthy text written with extensive jargon then it is not accessible to a general user and thus the ultimate goal of connecting with the public will not be met. Communicating in a clear and direct manner is not only the best practice, it is the law for federal agencies including the National Park Service and Bureau of Land Management.

There is more to a successful website than content; websites should be usable and engaging. There are widely accepted best practices in website design, layout, navigation, and accessibility. Of these areas, accessibility has the most clearly defined standards, which come from the World Wide Web Consortium (2005). Making the Web accessible is an effort to ensure that people with disabilities and aging adults can fully utilize the web as those without such barriers can (World Wide Web Consortium 2005). Without consideration of web accessibility, one would need full visual range to read pages, a certain level of literacy to understand the content, and the physical ability to maneuver a mouse and keyboard. For those with visual, auditory, physical, speech, cognitive, and neurological disabilities, websites must be developed in a way to be usable with assistive technologies so people can modify how they interact with a webpage (World Wide Web Consortium 2005). This is even more critical now that a great deal of everyday tasks are done online from paying bills to keeping in touch with loved ones. There are many 
technologies available to assist someone with using a website such as screen readers and alternative keyboards. For such tools to work properly, websites must be developed in a way that works with these tools and this varies in complexity depending on the size of the website and the type of content. Content can be made accessible by adding closed captioning to videos and "alt tags" to images (i.e. a description of a visual element that can be read by a screen reader to someone who is blind or has low vision).

\section{Qualitative Content Analysis}

Qualitative content analysis (QCA) is a flexible method of analysis allowing researchers to systematically describe narrative, and visual and other non-numeric source material to produce analyzable data in order to understand patterns in language, social ideas, memes, and more (Ackland 2013, Altheide and Schneider 2013, Elo and Kyngäs 2008, Neuendorf 2017, Schreier 2014). It is commonly used in social sciences, behavioral sciences and other disciplines that frequently study material that is visual (photos, video), verbal (speeches, lectures), user-generated (interviews, focus groups), or media content (newspaper articles, blog posts, websites). A core component to QCA methodology is using codes (e.g., words, phrases or themes) to classify language and content from the source material (Schreier 2014). Codes are words, phrases or images, as well as generalized messages or themes used to classify language and content. Researchers examine patterns and connections in codes among studied content to understand what messages are being communicated. The coding frame is the classification system itself. It encompasses the codes and tracks specific pieces of information in source material. Instead of classifying artifacts and features in QCA, we classify content of webpages 
(e.g., text, pictures, headings) into groups of like things which share attributes. Like any classification system, QCA allows one to assess trends in frequency of something (in this case, qualitative information).

QCA follows a series of steps. The first involves deciding on a research question, then selecting the material to be analyzed (Schreier 2014). Next is the developing of the coding frame, which happens in one of two ways: 1) start with existing concepts or themes and build codes from them (deductive), or 2) develop the coding frame through reading the material and identifying codes in a more organic fashion (inductive). Once the coding frame is created, the material must be segmented; in other words, determining whether the focus will be individual words, sentences, phrases or paragraphs. For consistency in analysis, a researcher should be explicit about how codes are applied and maintain the same segment size. Next, a sample of material should be coded to evaluate whether the coding frame is working as it should. After doing the test coding, the material should be reviewed to determine if the codes captured all of the important information the researcher may want to review later for analysis. Finally, adjustments should be made to the coding frame if necessary, before moving on to the full analysis.

\section{Intracoder Reliability}

When conducting qualitative and quantitative research, it is important to test the reliability of the data. For my project, I was especially interested in reliability, or consistency of the researcher's analysis (as opposed to intercoder reliability, or consistency across multiple individuals doing the coding) (Given 2008). Challenges that can impact intracoder reliability include the number of codes (possibly too few or too 
many), the time and resources available to do the analysis, and ambiguous definitions or parameters for each code (Given 2008).

\section{Computer-Assisted Qualitative Data Analysis}

Qualitative data analysis can be done by hand or utilizing computer-assisted qualitative data analysis (CAQDA) software like ATLAS.ti. Hand-coding processes and techniques will vary from researcher to researcher depending on their preferences for organizing information (Gibbs 2014). The coding by hand process often involves marking codes on hard copies of data with sticky notes or highlighters, then consolidating and grouping data by codes. Qualitative analysis software allows a researcher to complete the same process with greater speed and allows for more complex coding and analysis. In ATLAS.ti, one simply highlights an area of a document to create a "quotation" and applies codes to that quotation with one or two mouse clicks. A quotation is like an artifact that can be placed into multiple classifications, just like a stone tool could fall into classifications of shape, function, or raw material.

CAQDA software speeds up the analysis process and can help researchers keep track of data more efficiently (Gibbs 2014). These programs do not $d o$ the analysis for the researcher, but rather they can simplify comparisons among codes or identify situations where combinations of codes may not be intuitively obvious. For example, through exporting a simple report, a researcher could see instances where both stewardship and pseudoarchaeology are mentioned in websites to see if there is a consistent connection between the two in order to look closely at the context of those references. Such 
comparisons would be difficult and time-consuming to do by hand. A challenge of CAQDA is that it requires software training and technological skills in computer use. Although CAQDA was developed in the 1980s when personal computers began to be available, it was not widely used in academia until the early 2000s (Gibbs 2014). At present, most CAQDA include the same set of core features, which includes creating and managing code lists, ability to apply code to material, sophisticated text searches, and the ability to work with a wide variety of material types (text, images, videos, sound files) (Gibbs 2014). CAQDA software varies little in performance and preference between options comes down to some of the more minute differences between programs such as whether it is a Mac, Windows or web-based platform, or the cost.

For this study, I used ATLAS.ti as it is the CAQDA software offered through Portland State University. In order to use this software, I had to identify the source material (i.e., websites and specific webpages to be analyzed), the coding framework to use on those webpages, and define characteristics of each Franklin and Moe theme so I could code for the presence of those themes. 


\section{Chapter 3: Methods}

\section{Sampling Websites for Analysis}

My thesis research seeks to develop and apply a process for assessing archaeological websites, based on the extent the websites address the five themes outlined by Franklin and Moe (2012). To address this goal, I selected a sample of archaeology websites to study and then carried out QCA on a sample of pages within each website. With nearly 124 million archaeology-related websites in existence, initial website selection could be a daunting task. Since my goal was not to assess how extensively websites in general are communicating the five goals, but rather to develop an approach to assessment, I reasoned that studying $\sim 15$ websites ( $\sim 100$ webpages) provided sufficient contrast to assess the feasibility of QCA analysis itself, and of appropriate scale given the constraints of a thesis project.

In selecting websites to study, my first criterion was simply popularity, or specifically, the websites' prominence within search results of Google's proprietary search algorithm. The algorithm factors in elements including how frequently a website is visited, how keywords and phrases are used within a website's content, and accessibility elements within the coding, (https://www.google.com/search/howsearchworks/). I used an incognito Google Chrome browser window to search the term "archaeology." Using an incognito (sometimes called a private browsing window), removes any influence on the search results based on one's personal browsing history. I chose the term "archaeology" because it is sufficiently general and my goal was to assess the extent the websites are communicating Franklin and Moe's themes about archaeology. Further, I focused on websites devoted exclusively on archaeology and heritage, excluding ones 
that were linked to major media outlets (e.g., The Guardian, BBC, The Independent, National Geographic) because only a small number of their webpages were about archaeology. I also excluded Google advertisements and widgets that sometimes blend in with search results and any links to social media platforms (e.g., Twitter profiles, Reddit pages) as they were too fluid for my focused study. In addition, I only selected websites in English due to my personal linguistic constraints, but I did not limit the geographic focus of the website content. Then, with the above selection criteria in mind, I simply selected the 15 highest ranked websites in the Google results to study (Table 2). It is important to note that the ranking of a website on Google does not denote quality, but elements important to the Google algorithm like webpage visits, keyword use, and the time people spend on the websites.

When Google listed multiple webpages from the same website (e.g., Archaeological Institute of America's "home” webpage and their "news" webpage), I chose the first webpage that appeared in the search results. Figures 1a-c are screenshots from the first page of Google search results, which shows webpages and websites that were both included and not included in this project. To obtain the 15 websites that met my criteria, it was necessary to go to the fourth page of Google search results. 
Table 2: List of Websites Included in Thesis Project Analysis

\begin{tabular}{|c|c|c|c|c|c|}
\hline $\begin{array}{c}\text { Website } \\
\text { organization }\end{array}$ & $\begin{array}{l}\text { Google } \\
\text { rank }^{1}\end{array}$ & $\begin{array}{l}\text { Pages to } \\
\text { assess }\end{array}$ & $\begin{array}{l}\text { Origin } \\
\text { country }\end{array}$ & Category & Shorthand \\
\hline $\begin{array}{l}\text { Archaeology } \\
\text { Magazine }\end{array}$ & 1 & 8 & USA & Media outlet & Arch. Mag. \\
\hline $\begin{array}{l}\text { Society for American } \\
\text { Archaeology }\end{array}$ & 6 & 6 & USA & $\begin{array}{l}\text { Professional } \\
\text { organization }\end{array}$ & $\begin{array}{l}\text { Soc. for Amer. } \\
\text { Arch. }\end{array}$ \\
\hline $\begin{array}{l}\text { Archaeological } \\
\text { Institute of America }\end{array}$ & 9 & 9 & USA & $\begin{array}{l}\text { Professional } \\
\text { organization }\end{array}$ & $\begin{array}{l}\text { Arch. Inst. Of } \\
\text { Amer. }\end{array}$ \\
\hline $\begin{array}{l}\text { The Archaeology } \\
\text { Channel }\end{array}$ & 15 & 9 & USA & Media outlet & Arch. Channel \\
\hline $\begin{array}{l}\text { American Museum of } \\
\text { Natural History }\end{array}$ & 16 & 1 & USA & $\begin{array}{l}\text { Publicly accessible } \\
\text { space }\end{array}$ & $\begin{array}{l}\text { Amer. Mus. of } \\
\text { Nat. Hist. }\end{array}$ \\
\hline Carleton College & 17 & 7 & USA & Higher education & Carleton College \\
\hline $\begin{array}{l}\text { American Journal of } \\
\text { Archaeology }\end{array}$ & 18 & 8 & USA & Media outlet & $\begin{array}{l}\text { Amer. Journ. of } \\
\text { Arch. }\end{array}$ \\
\hline Mount Vernon & 22 & 7 & USA & $\begin{array}{l}\text { Publicly accessible } \\
\text { space }\end{array}$ & Mount Vernon \\
\hline University of Oxford & 23 & 11 & UK & Higher education & U. of Oxford \\
\hline Boston University & 24 & 8 & USA & Higher education & Boston Univ. \\
\hline $\begin{array}{l}\text { The Institute of } \\
\text { Archaeology }\end{array}$ & 28 & 10 & Israel & Higher education & Inst. of Arch. \\
\hline Trent University & 29 & 5 & Canada & Higher education & Trent Univ. \\
\hline $\begin{array}{l}\text { University of } \\
\text { Gothenburg }\end{array}$ & 33 & 6 & Sweden & Higher education & U. of Gothenburg \\
\hline University of Exeter & 34 & 7 & UK & Higher education & U. of Exeter \\
\hline City of Boston & 35 & 1 & USA & $\begin{array}{l}\text { Publicly accessible } \\
\text { space }\end{array}$ & City of Boston \\
\hline
\end{tabular}

Total number of webpages

103

\footnotetext{
${ }^{1}$ The Google rank exceeds the first 1-15 because I excluded results from social media platforms, media outlets, and multiple results from the same organization.
} 


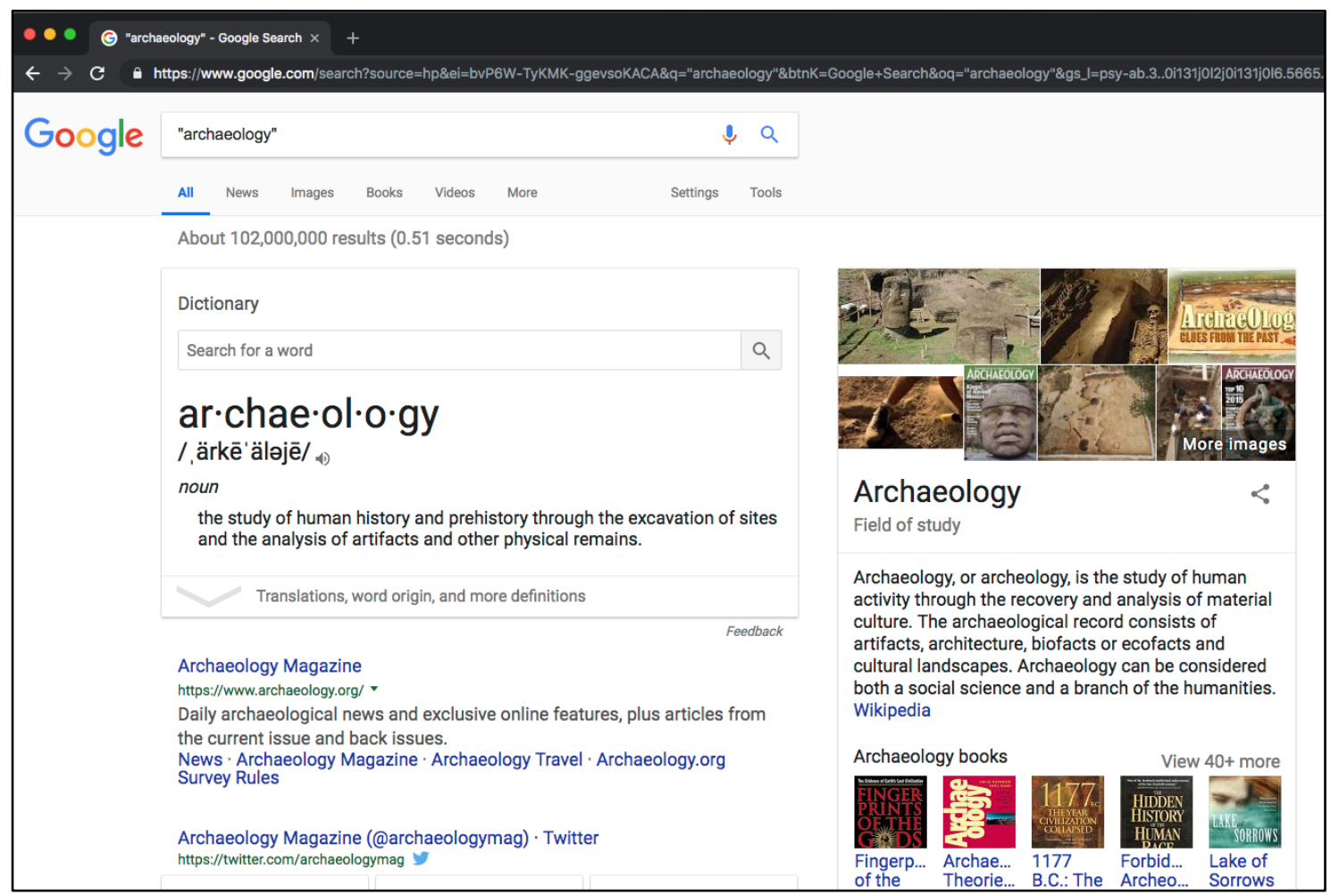

Figure 1a: A screenshot from the top of page one of the Google search results. Archaeology Magazine was included in this project, but their Twitter account was not as social media platforms were not considered websites. The definition on the right (pulled from Wikipedia) and the definition widget were ignored for the purposes of this project. 
Archaeological News from Archaeology Magazine - Archaeology ...

https://www.archaeology.org/news -

SOFIA, BULGARIA-Archaeology in Bulgaria reports that a solid gold

Christian reliquary purported to contain particles of the cross on which

Jesus Christ was ...

Archaeology - Wikipedia

https://en.wikipedia.org/wiki/Archaeology $~$

Archaeology, or archeology, is the study of human activity through the

recovery and analysis of material culture. The archaeological record

consists of artifacts, ...

Purpose - Methods · Academic sub-disciplines · Popular views of ...

\section{People also ask}

What are the types of Archaeology?

What is the average salary of an archaeologist?

Do Archaeologists make a lot of money?

Do archaeologists have to travel?

Archaeology | Science | AAAS

https://www.sciencemag.org/category/archaeology -

Study of fossil bones reveals same relatively low rate of skull fracture as modern humans. figurative artwork on a cave wall ...

Top stories

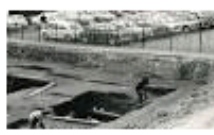

Treasure hunting: nine photos of archaeology in Oxfordshire

Figure 1b: The middle of Google's page one search results. The Archaeology Magazine webpage listed here was excluded because an Archaeology Magazine webpage appeared earlier that was included. Wikipedia was excluded because its content is generated by the general public. Science Magazine was excluded because it is a media outlet not focused on archaeology. I ignored the "people also asked" and the "top stories" widgets. 


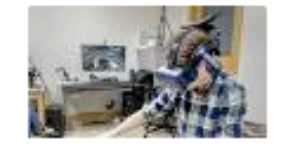

Dig this: VR lab lets UI archaeology students explore mammoth cave on campus

News-Gazette.com $\cdot 7$ hours ago

The ancient origins of werewolves

HeritageDaily $\cdot 2$ days ago

$\rightarrow$ More for "archaeology"

What is Archaeology? - Society for American Archaeology www.saa.org/Default.aspx?Tabld=1346

Archaeology is the study of the ancient and recent human past through material remains. It is a subfield of anthropology, the study of all human culture.

\section{Archaeology | Science | The Guardian}

https://www.theguardian.com/science/archaeology v

Oct 27, 2018 - Mummy found inside sarcophagus in Luxor tombs that also contained statues and figurines. Published: 25 Nov 2018. Mummified woman dating ...

\section{Archaeology - National Geographic}

https://www.nationalgeographic.com/archaeology-and-history/archaeology/ V

Dozens of photo galleries, articles, videos, and more tell the stories and reveal the mysteries of ancient cultures from around the world. Start your exploration ...

\section{Archaeological Institute of America - Archaeology - Site Preservation} https://www.archaeological.org/ -

:

Figure 1c: The bottom of Google's first page of results. I included the SAA and AIA in this project, but I excluded both the Guardian and National Geographic as nonarchaeology specific media outlets. 


\section{Selecting Webpages for Analysis}

After selecting the websites to assess, I needed to sample content within the websites in a logical and consistent way. Most websites have a "top navigation" bar comprised of a series of "tabs," which link to further topics. I reasoned that the pages linked to the tabs of the navigation bar could provide the sample for my study. The Archaeology Magazine home webpage (Figure 2), as well as each webpage linked to the tabs listed across the top navigation, "Home," "News," "Magazine," "Videos," "Podcasts," "Reader Info," "Travel," and "Subscribe," provided a total of eight webpages. My goal was to study the comparable parts of $\sim 15$ websites and between 100 120 webpages. The number of pages in the top navigation on most of the websites selected was 8-12 pages (though some were only one page). Some top navigation links had drop-down menus that listed a secondary navigation structure, which I ignored for this study because not all websites utilized a secondary navigation. In total, I assessed 103 webpages for the 15 websites.

I considered alternative approaches to selecting the webpages to assess on each of the 15 websites. For example, I could have assessed only the 15 specific webpages that appeared on the Google search results, but that would have been too small of a sample size to broadly understand the extent to which the Franklin and Moe themes were used and evaluate the QCA approach for website assessment. Another approach could have assessed the most visited webpages on each of the 15 websites, but that would have required access to the Google Analytics data and assumed all the websites had the tracking code installed. That was beyond the scope of this master's thesis. Also, I could have pre-determined specific types of webpages to assess like the "home" webpage, 
“contact" webpage, or "about us" webpage, however, most websites did not have that level of consistency with the same types of webpages beyond the "home" webpage.

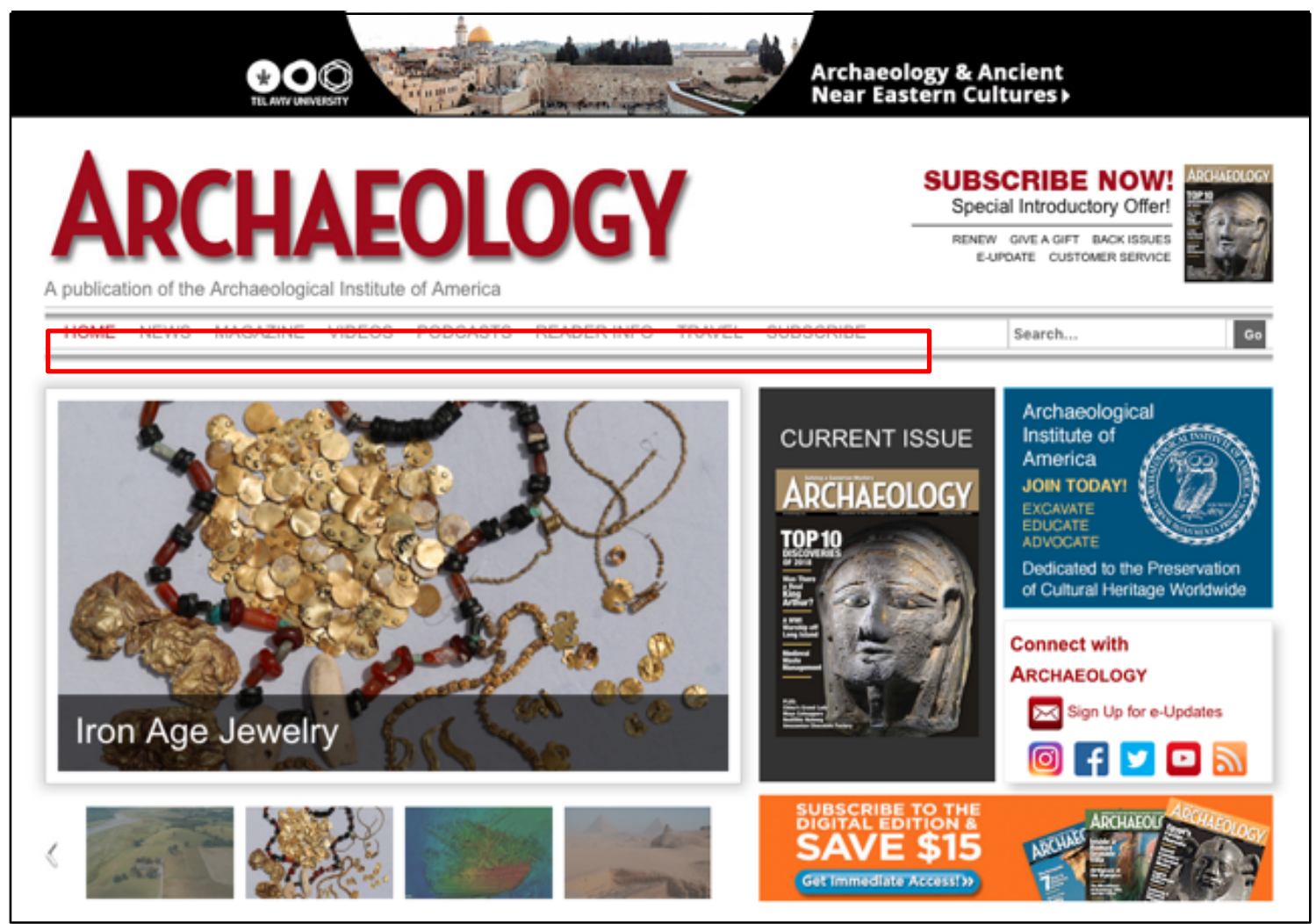

Figure 2: Screenshot from the Archaeology Magazine home webpage showing the top navigation.

I wanted to determine whether there was a connection between archaeology messaging and the amount of text on a webpage, so I went through each webpage in a web browser and copied all of the text into a Word document to get an approximate word count for each page. I then recorded those totals in a spreadsheet. 


\section{ATLAS.ti Training}

To complete the coding, I needed to learn how to use the ATLAS.ti software. In summer 2016, I attended a day of live training at the software's training headquarters in Corvallis, Ore. The bulk of my knowledge came from the free tutorial videos on the ATLAS.ti website, as well as additional support from both YouTube videos and a Facebook group dedicated to users of the software. In summer 2017, I developed a pilot coding scheme. Though it was a false start for the coding scheme I eventually used, it allowed me to refine my methods and this preliminary work gave me the confidence to develop this project.

\section{Preparing the Webpages for ATLAS.ti}

After selecting all of the websites and webpages to analyze, I developed a procedure for preserving a permanent digital record of each webpage that could be coded using ATLAS.ti software. Not only was this critical to being able to functionally import the webpages into ATLAS.ti, but the managers of the websites could potentially update the webpages at any time and I needed a stable version of the websites that I could refer to repeatedly throughout the thesis process. At the time of this research, ATLAS.ti did not accept importing a URL to code a website "as-is" and I discovered that the best file format to use was a PDF. Unfortunately, when I tried to save each webpage as a PDF out of the browser, much of the formatting and images was lost and the webpages became incomplete. I decided to save each webpage using the "save as webpage, complete" option, which created an HTML file that allowed me to see the website in its entirety using a browser. However, ATLAS.ti did not accept that file format. I ultimately took 
screenshots of every webpage. Most webpages in my sample required multiple screenshots to capture the full length of the page as I was limited to what I could see on my monitor, so I needed a way to combine all of the screenshots into a single document. I put all of the screenshots for a single webpage in sequence into a Microsoft Word document then exported each of those Word documents as separate PDFs, which was a compatible file format for ATLAS.ti. I created the records in November and December 2018, which took approximately 17 hours.

\section{Organizing the Webpages in ATLAS.ti}

Once the files were ready to import into ATLAS.ti, I needed to decide the order I would code them. I could have systematically worked through each of the 15 websites in order as they appeared in the Google search results, then worked left-to-right on the webpages across the top navigation of each website. However, that approach could have led to systematic difference in how I coded the websites as my learning evolved. I addressed this in two ways. First, I decided to randomize the order of the webpages and code them in that order as opposed to doing one complete website at a time (e.g., doing all AIA webpages before moving onto all SAA webpages). Second, I re-analyzed the first $10 \%$ of the webpages that were coded early on, which allowed me to assess the intracoder reliability.

My process for randomizing the webpages began by uploading a list of the 103 webpages to a list randomizer tool. I selected random.org/lists because it appeared first on a Google search for such a tool. Random.org produced a random sequence of the webpages (see Figure 3 for a screenshot of a portion of the randomized list). I then re- 
named the PDFs I had created for each webpage to match that random number as well as listing the associated number in the master table I used to track information on each webpage. Finally, I imported the PDFs into ATLAS.ti and the software automatically arranged them chronologically by filename. Once I began coding, I started with the file named " 1 " and went through them in order.

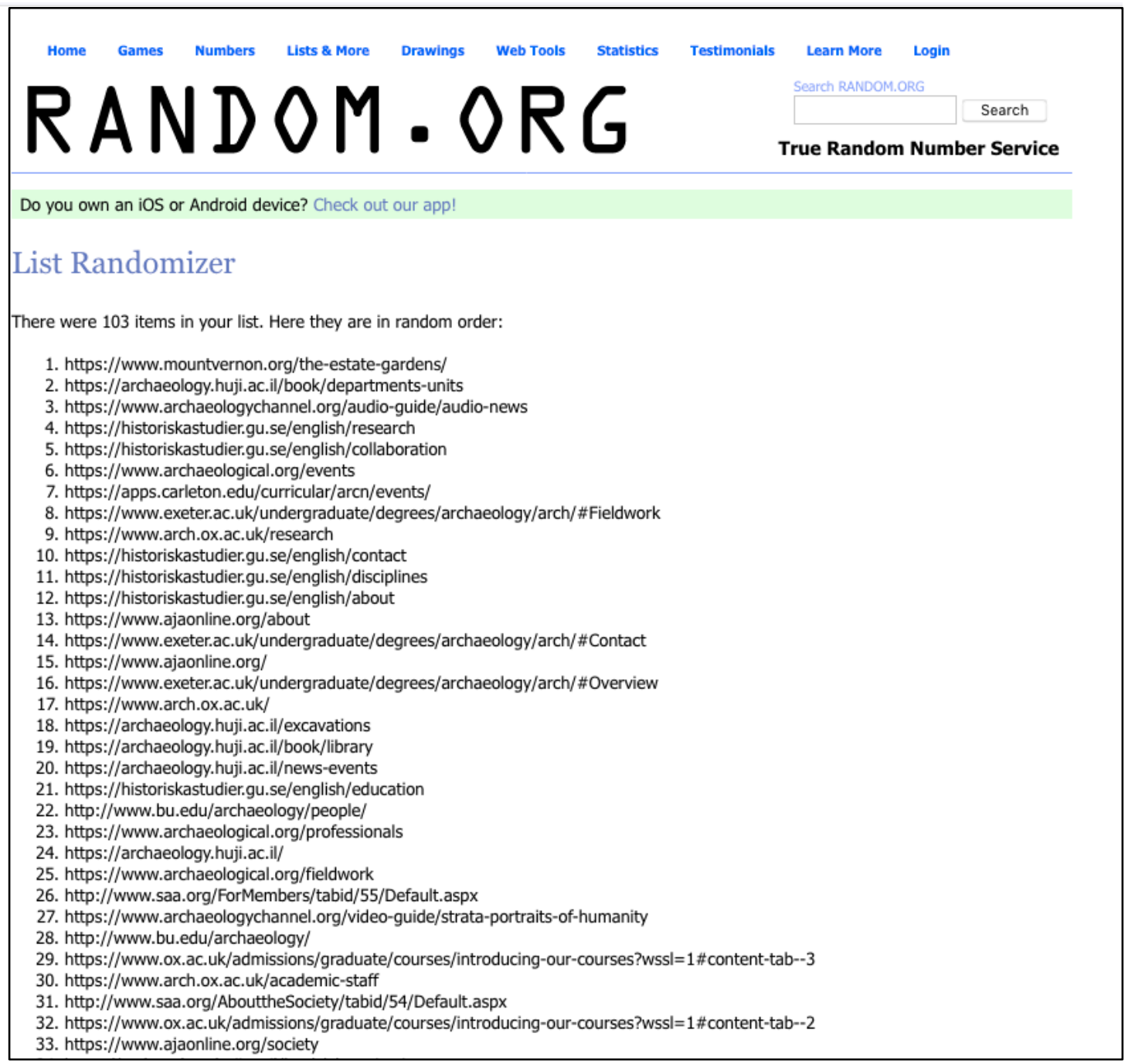

Figure 3: A screenshot of the Random.org list randomizer used to assign numbers to each webpage. 


\section{Developing a Coding Frame and Segment Length}

The final stage before I began to code each webpage was to create my list of codes. Codes provide a streamlined way to track data during analysis so I had to anticipate potential data comparisons I would need to ensure I used relevant codes. For example, I knew I would want to understand which websites and webpages had the highest frequency of Franklin and Moe themes to see if there were any connections between type of organization (e.g., media outlet, university) and the themes they emphasized on their webpages. Such an analysis required me to use codes for each website and each theme as ATLAS.ti has the ability to easily export tables comparing frequency of codes. If I had later discovered a data point I needed and had not already tracked it, I would have had to go back through all the webpages and code for that element. Ultimately, I decided to track three primary areas: Franklin and Moe themes (5 codes), website name/organization (15 codes), and webpage element ( 8 codes) (see Figure 4 for a screenshot code structure from ATLAS.ti).

I had initially considered a much more robust coding frame that would allow for quantitative analysis of keywords. Specifically, I explored adding codes for keywords I expected to encounter for each theme (e.g. "stewardship" for Stewardship or “excavation” for Fundamental Concepts). However, through various iterative processes and ATLAS.ti training during the thesis proposal stage, I learned that such fine grain coding would be too restrictive. I would not have been able to anticipate all of the possible phrases that would convey a theme and the themes were often expressed through imagery or phrases. 
In conjunction with defining the coding frame, I had to determine the segment length (i.e., the size of the "quotation" in ATLAS.ti). Common segment sizes are a word, sentence or paragraph. Given that this research explored more than text (e.g., images, videos), I had to identify a way to be as equitable as possible with my segmentation. For visual elements, I segmented by creating a quotation for each image or video I wanted to track. Segmenting by word was too narrow because it assumed the Franklin and Moe themes could be conveyed in a single word. Selecting entire paragraphs as a segment was too broad because multiple themes could be conveyed in a single paragraph. For text, I decided to segment by phrase or sentence because that was equitable between link and navigation names, headlines, bulleted lists in body text, and sentences in body text. 
$\nabla \ll$ Code Groups (3)

$\nabla \ll$ F\&M themes

$\geq$ Access to archaeology

$\geq$ Archaeological content

$\geq$ Fundamental concep...

$\geq$ Stewardship \& prese...

$\geq$ Uses of archaeology

$\nabla \ll$ Webpage element

$>$ Body text

$>$ Caption

$>$ Graphic

$>$ Headline

$>$ Link name

$>$ Photo

$>$ Subhead

Video

$\checkmark \ll$ Website organization

$\checkmark$ American Journal of A...

American Museum of...

Archaeological Instit...

Archaeology Magazine

Boston University

Carleton College

City of Boston

Mount Vernon

Society for American...

The Archaeology Chan...

The Institute of Archa...

Trent University

University of Exeter

University of Gothenb...

University of Oxford

Figure 4: A screenshot of the three code groups and individual codes within ATLAS.ti. I assigned a color to each group to visually differentiate the codes. 


\section{Defining the Franklin and Moe Themes}

With the files in place and the coding frame developed, I needed to define the Franklin and Moe themes before I could begin coding in order to code webpage content as accurately and consistently as possible. Defining the themes was significantly more subjective than simply coding for webpage element or website name/organization. Franklin and Moe (2012) provide overviews of each theme, which was a starting place for my definitions. I expanded the definitions as I saw examples of the themes in action on websites.

Access to Archaeology

Franklin and Moe explained this theme as participatory archaeology, where archaeologists involve "stakeholders in the educational process" (2012:575). Such involvement can lead people to preserve their own heritage. I suggest "Access to Archaeology" (Access) should include more than particular stakeholders, but rather any action that explicitly connected archaeology with the public. Thus, examples I linked included:

- Discussion of archaeology-themed days and months around the world

- Information on how to access archaeological information in museums and libraries

- Specific archaeology events (e.g. conferences or site tours)

- Specific events to learn more about archaeology (e.g., conferences, speakers, site tours)

- Links to social media accounts to connect with archaeologists and archaeology organizations

- Opportunities to connect directly with an archaeologist (see Figure 5, a screenshot from the American Museum of Natural History's 
"archaeology" page, which offered visitors an opportunity to ask an archaeologist about mummies)

- Scholarship information for students to get field experience

- Virtual tours of archaeological sites

- Free online videos, lectures, podcasts

\section{Ask a Scientist about Mummies}

Archaelogist David Hurst Thomas answers kids' questions.

Figure 5: Example of the Access from the American Museum of Natural History's "archaeology" webpage.

\section{Archaeological Content}

To Franklin and Moe (2012), “Archaeological Content” (Content) focuses on how people lived in the past (particularly so living peoples can compare their lives to those who lived in the past) and includes specific details and findings. They also listed some elements of this theme, including significant archaeological sites, changes in archaeological practice, and important archaeological debates (2012:576). Ways this theme was illustrated on webpages include:

- Information about specific archaeological sites and locations around the world (see Figure 6 from The Archaeology Channel's "home" webpage)

- Descriptions and listings for lectures about research projects and archaeological sites

- Content of lectures and presentations

- Research focus areas for academic departments and faculty

- News articles about specific sites, archaeological developments, and research projects

- Descriptions about past peoples, their way of life, how they satisfied basic needs 


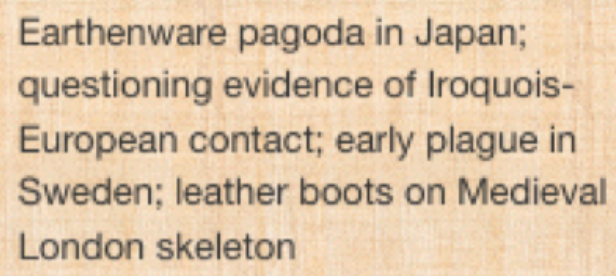

Figure 6: Example of Content from The Archaeology Channel's "home" webpage

Fundamental Concepts of Archaeology

Franklin and Moe defined "Fundamental Concepts of Archaeology"

(Fundamental Concepts) theme as archaeological methodology (e.g., field and lab methods, dating methods, excavation methods), understanding context, and knowing how "archaeologists construct knowledge about the past" (2012:573-4). Given that their article was in the context of archaeological education, they discussed ways this theme may be present in classroom and other educational settings. Building from their examples, and others I found on webpages, I created a list of ways this theme may present itself on websites:

- Photos and videos of fieldwork, archaeological sites, and artifacts (see Figure 7, a photo from the AIA's "home" page, showing someone taking notes in the field)

- Descriptions of specific archaeological methodologies (e.g., in college course descriptions)

- Technological advancement in archaeological methods and tools

- Explicit explanations of what archaeology is and how it is done (see Figure 8 from the SAA's "what is archaeology" webpage, helping define archaeology)

- Descriptions of the archaeological subfields 


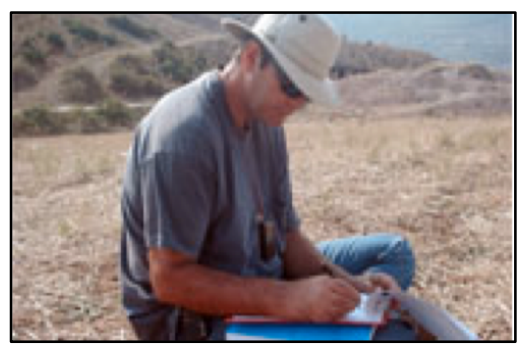

Figure 7: Example of Fundamental Concepts from a photo on the AIA's "home" webpage

An archaeological site is any place where physical remains of past human activities exist. There are many, many types of archaeological sites.

Figure 8: Example of Fundamental Concepts from the SAA's "what is archaeology" webpage

Stewardship \& Preservation

A primary focus of archaeology is to protect archaeological sites and the scientific data contained within. Franklin and Moe (2012) detailed specific programs, laws, and mandates that aid in such efforts (e.g., Archaeological Resources Protection Act) and they cited examples of archaeological education programs developed to inspire stewardship among the public and future generations (e.g., Project Archaeology). The "Stewardship and Preservation" (Stewardship) theme appeared on webpages in ways such as:

- Statements of conservation, preservation and stewardship as ideals

- Advertisements for fields schools and specific organizations that have a preservation and conservation focus

- Descriptions of preservation activities at specific sites (see Figure 9, which shows "preservation" as a link within the websites" top navigation and giving the topic prominence) 
- Donation requests were on some pages, specifically requesting financial support for preservation projects and initiatives

- Specific laws, programs, and federal mandates

Figure 9: Example of Stewardship theme from Mount Vernon's “archaeology" webpage showing the entire top navigation on that website. The "preservation" navigation link was a coded segment.

\section{Uses of Archaeology}

For "Uses of Archaeology" (Uses), Franklin and Moe (2012) discussed ways archaeology can be used outside of archaeology proper, such as helping children understand scientific methods, teaching critical thinking and real-world problem solving, and promoting social justice (2012:574-5). There was crossover with Stewardship in regard to how archaeology can be used to help people feel connected to their past and feeling pride in their heritage. Using Franklin and Moe's discussion as a foundation, the following are ways this theme was coded on archaeology websites:

- Interdisciplinary connections within college course listings, degree requirements, and related majors to archaeology (see Figure 10 from Carleton College's Archaeology department's "home" webpage showing how students studying archaeology can use their skills in other disciplines)

- Listings of faculty research projects and areas of focus connecting to fields outside of archaeology

- Descriptions of non-archaeology careers that an archaeology degree can support

- Explanations of how archaeology informs heritage and demonstrations of how combining archaeology with other disciplines can tell a story about specific people and places

- Information about how archaeology was used to address problems or issues in other disciplines 


\section{Archaeology concentrators since 1991 have majored in: Studio Art, Art History, Biology, Chemistry, Classical Languages, Geology, History, Political Science, Psychology, Religion, and Sociology and Anthropology.}

Figure 10: Example of Uses from Carleton College's archaeology department "home" webpage.

\section{Applying Codes}

With an understanding of the boundaries for each theme, I began creating quotations and applying codes to them within ATLAS.ti. The software allowed me to apply multiple codes to each quotation, even multiples from the same group if a situation called for it. I did not apply codes to all content on the webpages, but rather the content that was directly applicable to the Franklin and Moe themes. If a segment did not connect to one of the Franklin and Moe themes, I did not apply a code for the website or webpage element either.

To illustrate how I applied the codes, I present screenshots from ATLAS.ti coding for Archaeology Magazine’s "magazine" webpage (Figures 11a-b). I labeled four of the quotations to demonstrate a variety of ways I applied codes (e.g., different codes, applying multiple codes to one quotation) and will explain my reasoning for coding the Franklin and Moe themes as I did. For quotations A-C, I selected Content as the theme because they are promising or listing specific archaeological sites and finds. Quotation D is more complex so I chose to apply three Franklin and Moe themes to it. The quotation (i.e., segment size) was the entire image with several messages conveyed in it. I chose Content because it names Crow Canyon Archaeological Center as a specific archaeological site; I chose Access because the content within the graphic is inviting 
people to the center and to participate in archaeological work; and I chose Fundamental Concepts because the text on the graphic specifies that lab work and excavation work are archaeological activities. Most quotations were only linked to one theme, but some were more complex as evidenced in quotation D (Figure 11b).

I reviewed the approximate total time I spent in coding all of the webpages and each webpage took about two-to-10 minutes to fully code. The length of the page and density of the content impacted how long it took. In total, I spent approximately 10 hours coding the 103 webpages in December 2018. 


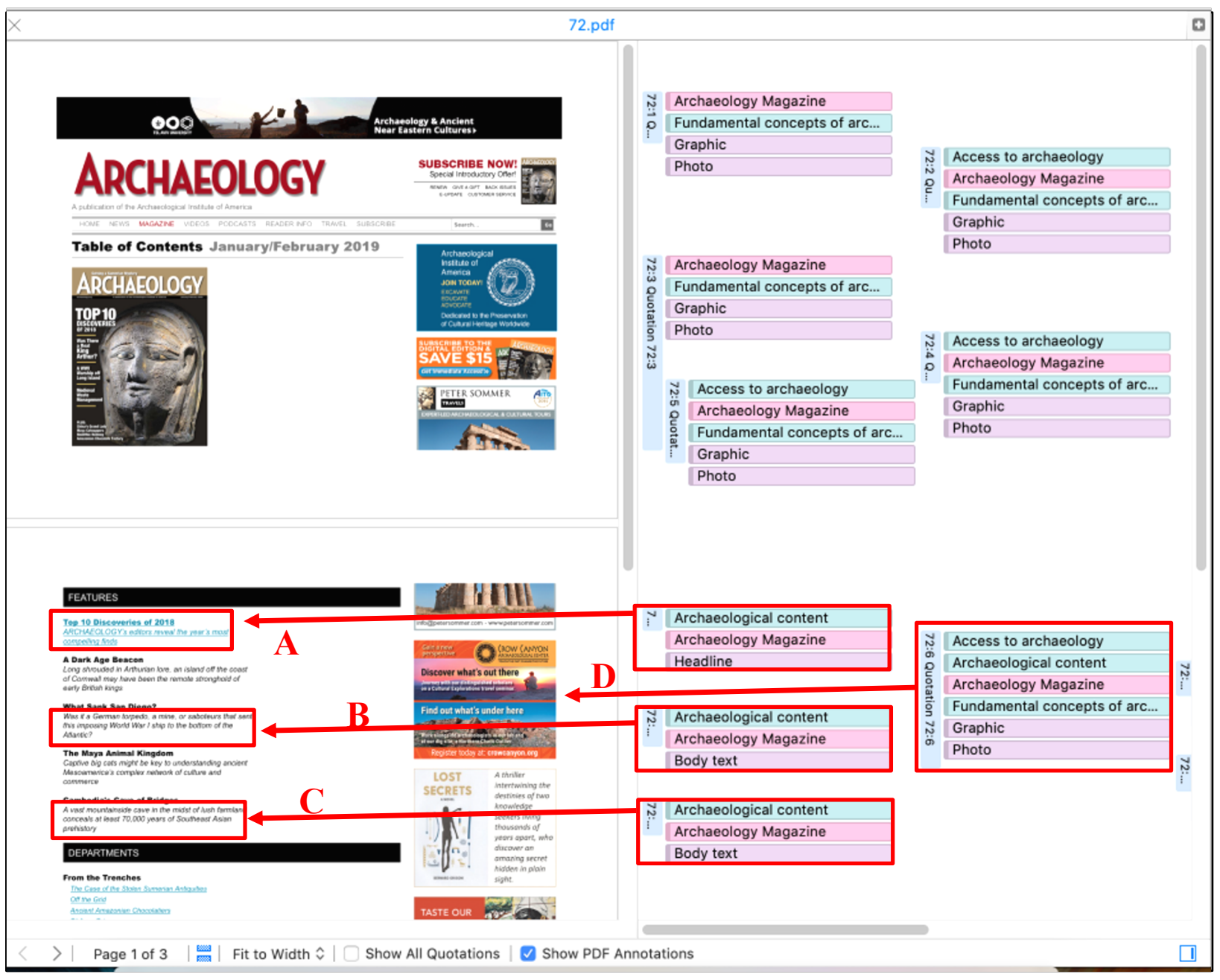

Figure 11a: A screenshot from Archaeology Magazine in ATLAS.ti, demonstrating the connection between a quotation and codes I applied. The quotation is the image in the red box on the left and four codes were applied to it (red box on the right). 


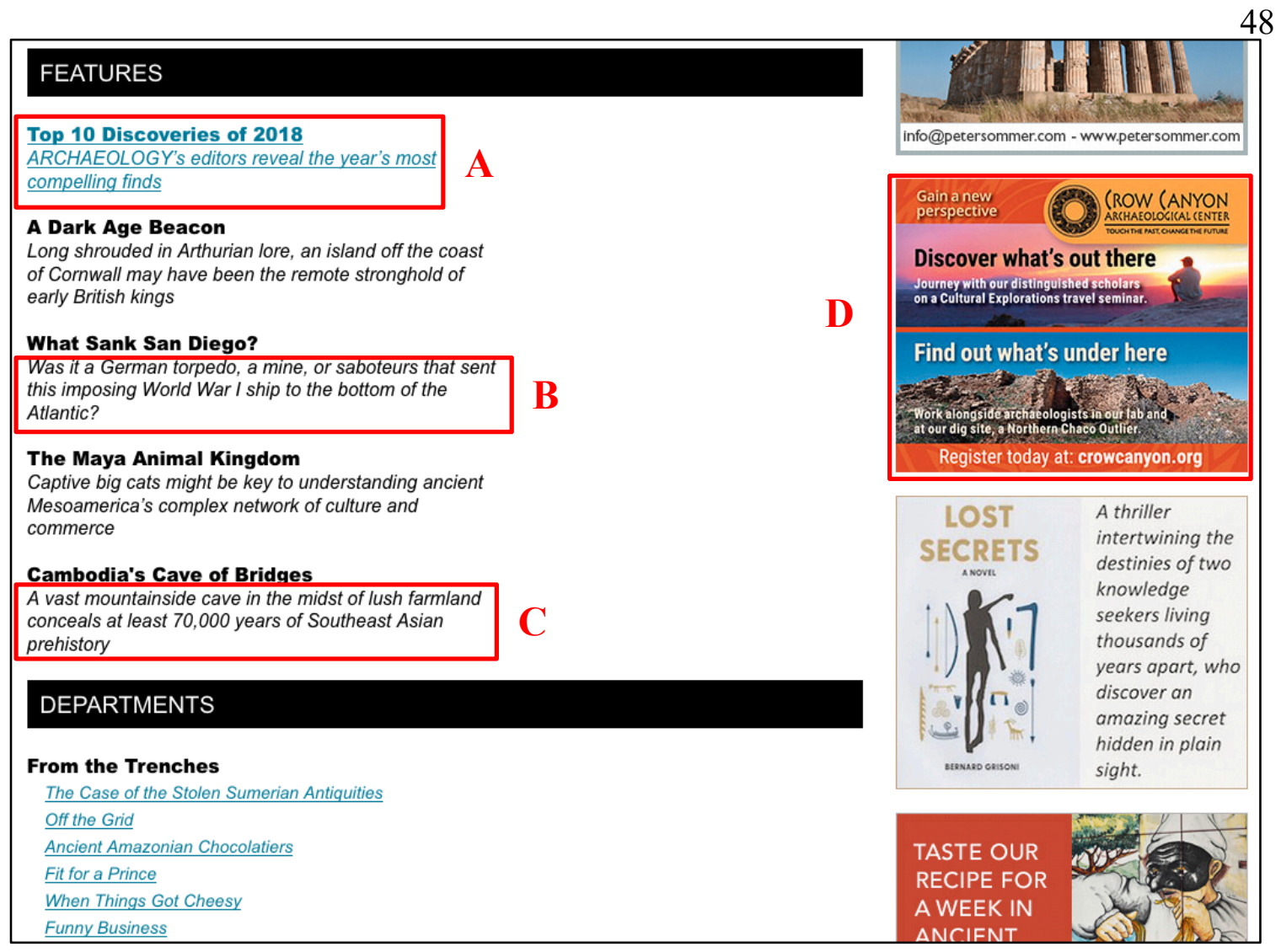

Figure 11b: This screenshot is a close-up view of content outlined in Figure 11a.

\section{Intracoder Reliability}

Lastly, I wanted to understand the extent to which my coding was internally consistent. I reasoned that re-coding 10 webpages, or approximately $10 \%$ of the total sample, was appropriate to gauge my consistency in applying the theme codes. After I completed coding the 103 pages, I re-uploaded the first 10 webpages I had coded into ATLAS.ti, but I altered the filenames so I could track which were the re-coded ones and which were the originally coded webpages. Between five and 10 days separated the original coding pass and the re-coding. The time involved is included in the 10 hours overall. 


\section{Summary}

In summary, I developed a method to select and conduct a QCA on archaeology websites. This method included using Google's proprietary search algorithm to identify the 15 most popular archaeology-related websites. I then used the "top navigation" of those websites to select 103 webpages to assess. I created static records of each webpage by creating PDFs of screenshots of each webpage and established a coding framework of traits to code for. After completing an initial pass through the 103 webpages, I re-did the analysis of the first 10 webpages I coded to assess intracoder reliability. 


\section{Chapter 4: Results}

The purpose of this research project was to develop and apply an assessment method to a sample of archaeology-focused websites. Before reviewing results, I consider the intracoder reliability of the QCA by comparing results from an early coding of a sample of webpages with a later coding. Then I examine the extent to which Franklin and Moe's five themes were used among the 15 of the most popular archaeology websites selected for my study. Next, I categorize the webpages by content function to look for trends. I then consider webpage word count and "body text" (webpage element) frequency to explore whether there is a connection between "sample size" (the size and extent of a webpage) and the number of archaeology messages. Finally, I share exemplary ways these themes have been highlighted.

\section{Intracoder Reliability}

To verify the reproducibility of my results, I re-analyzed (applied the same coding to) the first 10 webpages ( $9.7 \%$ of total pages) in this study after completing the initial coding of all 103 webpages (Table 3). While there are differences, overall these are small, mainly between frequencies of 0 and 1 . With Access for example, the difference in eight of the 10 webpages was between 0 and 1 , with a median difference of zero and a mean of 0.7. The differences were slightly higher for Content and Fundamental Concepts, with means/medians of $1.3 / 1$ and 2/0.5, respectively. Consistency in coding for Stewardship and Uses was high, even higher than shown for Access (Table 3). 
Table 3: A Comparison of Coding Results Between First and Second Coding Passes on Webpages 1 Through 10.*

Website (Webpage Label) Access Content Fund. Conc. Steward. Uses

\begin{tabular}{|c|c|c|c|c|c|}
\hline Mount Vernon (The Estate) 1st Coding & 4 & 1 & 0 & 2 & 0 \\
\hline Recode & 3 & 0 & 0 & 2 & 0 \\
\hline Difference & 1 & 1 & $\mathbf{0}$ & $\mathbf{0}$ & $\mathbf{0}$ \\
\hline $\begin{array}{l}\text { The Instit. of Arch. (Depts. \& Labs) 1st } \\
\text { Coding }\end{array}$ & 0 & 1 & 4 & 0 & 0 \\
\hline Recode & 0 & 1 & 4 & 0 & 0 \\
\hline Difference & $\mathbf{0}$ & $\mathbf{0}$ & $\mathbf{0}$ & $\mathbf{0}$ & $\mathbf{0}$ \\
\hline The Arch. Channel (Audio News) 1st Coding & 0 & 12 & 2 & 0 & 0 \\
\hline Recode & 0 & 12 & 1 & 0 & 0 \\
\hline Difference & $\mathbf{0}$ & $\mathbf{0}$ & 1 & $\mathbf{0}$ & $\mathbf{0}$ \\
\hline Univ. of Gothenburg (Research) 1st Coding & 1 & 17 & 7 & 0 & 1 \\
\hline Recode & 1 & 18 & 1 & 0 & 1 \\
\hline Difference & $\mathbf{0}$ & 1 & 6 & $\mathbf{0}$ & $\mathbf{0}$ \\
\hline $\begin{array}{l}\text { Univ. of Gothenburg (Collaboration) 1st } \\
\text { Coding }\end{array}$ & 1 & 0 & 0 & 0 & 0 \\
\hline Recode & 1 & 0 & 0 & 0 & 0 \\
\hline Difference & $\mathbf{0}$ & $\mathbf{0}$ & $\mathbf{0}$ & $\mathbf{0}$ & $\mathbf{0}$ \\
\hline Arch. Inst. of Amer. (Events) 1st Coding & 5 & 4 & 2 & 0 & 0 \\
\hline Recode & 6 & 1 & 5 & 2 & 0 \\
\hline Difference & 1 & 3 & 3 & 2 & $\mathbf{0}$ \\
\hline Carleton College (Events) 1st Coding & 0 & 2 & 1 & 0 & 0 \\
\hline Recode & 0 & 1 & 1 & 0 & 0 \\
\hline Difference & $\mathbf{0}$ & 1 & $\mathbf{0}$ & $\mathbf{0}$ & $\mathbf{0}$ \\
\hline Univ. of Exeter (Fieldwork), 1st Coding & 0 & 2 & 9 & 0 & 3 \\
\hline Recode & 3 & 3 & 6 & 0 & 3 \\
\hline Difference & 3 & 1 & 3 & $\mathbf{0}$ & $\mathbf{0}$ \\
\hline Univ. of Oxford (Research) 1st Coding & 0 & 8 & 1 & 0 & 0 \\
\hline Recode & 0 & 2 & 8 & 0 & 0 \\
\hline Difference & $\mathbf{0}$ & 6 & 7 & $\mathbf{0}$ & $\mathbf{0}$ \\
\hline Univ. of Gothenburg (About Us) 1st Coding & 2 & 0 & 0 & 0 & 0 \\
\hline Recode & 0 & 0 & 0 & 0 & 0 \\
\hline Difference & 2 & $\mathbf{0}$ & $\mathbf{0}$ & $\mathbf{0}$ & $\mathbf{0}$ \\
\hline Mean Difference & 0.7 & 1.3 & 2 & 0.2 & 0 \\
\hline Median Difference & 0 & 1 & 0.5 & 0 & 0 \\
\hline Freq of Codes (1st Coding) & 13 & 47 & 26 & 2 & 4 \\
\hline
\end{tabular}

\footnotetext{
* Shaded cells showed high discrepancies. See text for discussion.
} 
While overall, these comparisons suggest high intracoder reliability, in three cases across two webpages, there were substantial differences in coding (see shaded cells Table 3), which deserve further attention for possible impact on my results. On the University of Gothenberg's "Research” webpage coding for Fundamental Concepts, I counted seven instances in the first pass but only one instance in the second. For Fundamental Concepts on the University of Oxford's "Research" webpage, I counted only one instance in the first pass, but eight in the second pass. I also was highly inconsistent in coding the same University of Oxford webpage for the Content theme, coding eight examples in the first pass, but only two in the second pass.

Looking closely at the University of Gothenburg discrepancies, the differences came from inconsistency in the use of Content and Fundamental Concepts, where I tended to use the Fundamental Concepts code more initially, and Content on the second pass. By the second pass, I had reasoned that Content quotations should demonstrate specific archaeological results (i.e., site name, time period, findings) and Fundamental Concepts could more broadly indicate methodology (i.e., excavation, lab work, artifacts) without specific information connected to results. In other words, Fundamental Concepts is more the "how" and Content is more the "who/what/where/when."

When comparing coding passes of the University of Oxford webpage in detail, most of the differences came from inconsistency in the use of Content and Fundamental Concepts, as with University of Gothenburg, but I tended to use the Content code more initially, and Fundamental Concepts on the second pass. [In one instance, I did not create a quotation on the second pass that I had made on the first, which resulted in one fewer segments to code.] On the first pass, I thought quotations were Content, but it was too 
vague to identify to a specific site so I determined those were more broadly methodology. One example of this was a photo of a grouping of human bone fragments (Figure 12) that on the second pass I determined was more linked to archaeological inquiry (Fundamental Concepts) than descriptive of finds from a particular grave site or human population (Content).

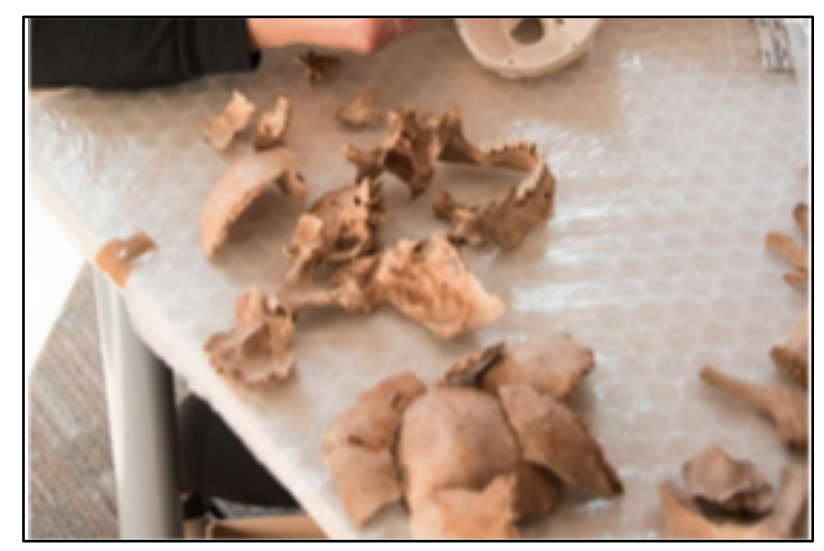

Figure 12: A collection of human remains from unknown site, University of Oxford webpage. On the first pass, coded as Content; on the second pass as Fundamental Concepts.

In sum, the differences in coding between the first and second pass are relatively minor. The greatest discrepancies relate to differentiating Content and Fundamental Concepts. As seen below, these two themes are the most dominant in frequency across the webpages in my study and the extent that I applied one or the other to the content analysis would not alter this general pattern. I used the first pass frequencies in the summary results in the following sections. 


\section{Overview of Coding}

As described in Chapter 3, my analysis involved learning how to use ATLAS.ti and developing my process, which took approximately 40-60 hours. I then had to prepared the webpage records and import them into ATLAS.ti as PDFs, which took approximately 17 hours. I then systematically reviewed each webpage in an order produced by a random number generator, and applied appropriate codes representing the Franklin and Moe theme(s), webpage element(s), and website organization. The QCA coding process took approximately 10 hours, which included re-coding the first 10 webpages to determine my intracoder reliability.

\section{To What Extent are the Franklin \& Moe Themes Used Within Archaeology Websites?}

My primary interest was to understand the extent to which the Franklin and Moe themes were used within archaeology websites and to determine whether these five themes sufficiently captured archaeology website content. The Franklin and Moe themes occurred a total of 1,151 times across the 103 webpages (Table 5). In my analysis, specific webpage elements could have been assigned to multiple themes so the total number of themes $(1,151)$ is slightly greater than the total number of elements $(1,098)$. Two of the webpages had technical errors and were not included in the study, which gave me a robust sample of 101 webpages to code.

The most common themes were Fundamental Concepts (frequency 437), followed by Content (304) and Access (219). Stewardship and Uses were represented in much lower frequencies, 96 and 95, respectively (Table 4). The mean and median of 
Fundamental Concepts and Content were 29.1/23 and 20.3/17, respectively. Conversely, the mean and median for the least frequent themes of Stewardship and Uses were 6.4/1 and $6.3 / 4$, respectively.

Table 4: The Frequency of Each Theme Overall and Per Website

\begin{tabular}{|c|c|c|c|c|c|c|c|}
\hline Website & $\begin{array}{c}\text { Num. of } \\
\text { webpages }\end{array}$ & Access & Content & Fund. Conc. & Steward. & Uses & Code totals \\
\hline $\begin{array}{l}\text { Arch. Inst. of } \\
\text { Amer. }\end{array}$ & 9 & 65 & 10 & 85 & 49 & 4 & 213 \\
\hline Arch. Mag. & $8^{*}$ & 23 & 55 & 64 & 1 & 5 & 148 \\
\hline Univ. of Exeter & 7 & 5 & 29 & 62 & 1 & 39 & 136 \\
\hline $\begin{array}{l}\text { Soc. for Amer. } \\
\text { Arch. }\end{array}$ & 6 & 32 & 15 & 33 & 9 & 12 & 101 \\
\hline The Arch. Channel & 9 & 15 & 38 & 25 & 6 & 6 & 90 \\
\hline Mount Vernon & 7 & 9 & 22 & 17 & 25 & 1 & 74 \\
\hline Instit. of Arch. & 10 & 4 & 17 & 39 & 1 & 2 & 63 \\
\hline Carleton College & 7 & 10 & 18 & 23 & 0 & 8 & 59 \\
\hline Trent Univ. & 5 & 16 & 10 & 13 & 2 & 7 & 48 \\
\hline Univ. of Oxford & $11^{*}$ & 1 & 35 & 10 & 0 & 2 & 48 \\
\hline $\begin{array}{l}\text { Univ. of } \\
\text { Gothenburg }\end{array}$ & 6 & 6 & 22 & 11 & 0 & 3 & 42 \\
\hline Boston Univ. & 8 & 6 & 3 & 25 & 0 & 6 & 40 \\
\hline City of Boston & 1 & 12 & 12 & 9 & 2 & 0 & 35 \\
\hline $\begin{array}{l}\text { Amer. Mus. of Nat. } \\
\text { Hist. }\end{array}$ & 1 & 9 & 8 & 16 & 0 & 0 & 33 \\
\hline $\begin{array}{l}\text { Amer. Journ. of } \\
\text { Arch. }\end{array}$ & 8 & 6 & 10 & 5 & 0 & 0 & 21 \\
\hline Total & 103 & 219 & 304 & 437 & 96 & 95 & 1,151 \\
\hline Mean & 6.9 & 14.6 & 20.3 & 29.1 & 6.4 & 6.3 & 76.7 \\
\hline Median & 7 & 9 & 17 & 23 & 1 & 4 & 59 \\
\hline
\end{tabular}


There was wide variation across websites in the frequency at which the themes were present. For example, the AIA provided 213 instances, while the American Journal of Archaeology only generated 21 (Table 4). Given that the actual number of webpages per website also differs, it seemed reasonable to consider that this factor alone may account for this wide variation. To examine this possibility, I plotted the number of webpages against the frequency that themes were present (Figure 13). The relationship is complex, but overall, there is not a strong link between number of webpages and number of codes. Two websites with only one webpage (City of Boston and American Museum of Natural History), have a low frequency of themes (35 and 33 respectively) but three websites with eight pages generated a broad range of theme frequencies: 148 (Archaeology Magazine), 40 (Boston University) and 21 (American Journal of Archaeology). The website with the highest theme frequency (213, AIA) did not have the highest number of webpages (9). The website with the highest number of webpages (11, University of Oxford), only generated a modest frequency of themes (48).

Clearly, simply having a lot of webpages does not ensure a website will have a high presence of the Franklin and Moe themes. Two factors likely contribute to this. First, archaeology itself may be only a small part of the organization's focus, so one should not expect all or even most pages of the website to feature archaeology. This applies to all the higher education-based websites, which include information on many topics unrelated to archaeology since the organizations are much larger than the archaeology-related departments. Second, there has been a growing website design trend in recent years that favors webpages of longer lengths that are visually broken up into 


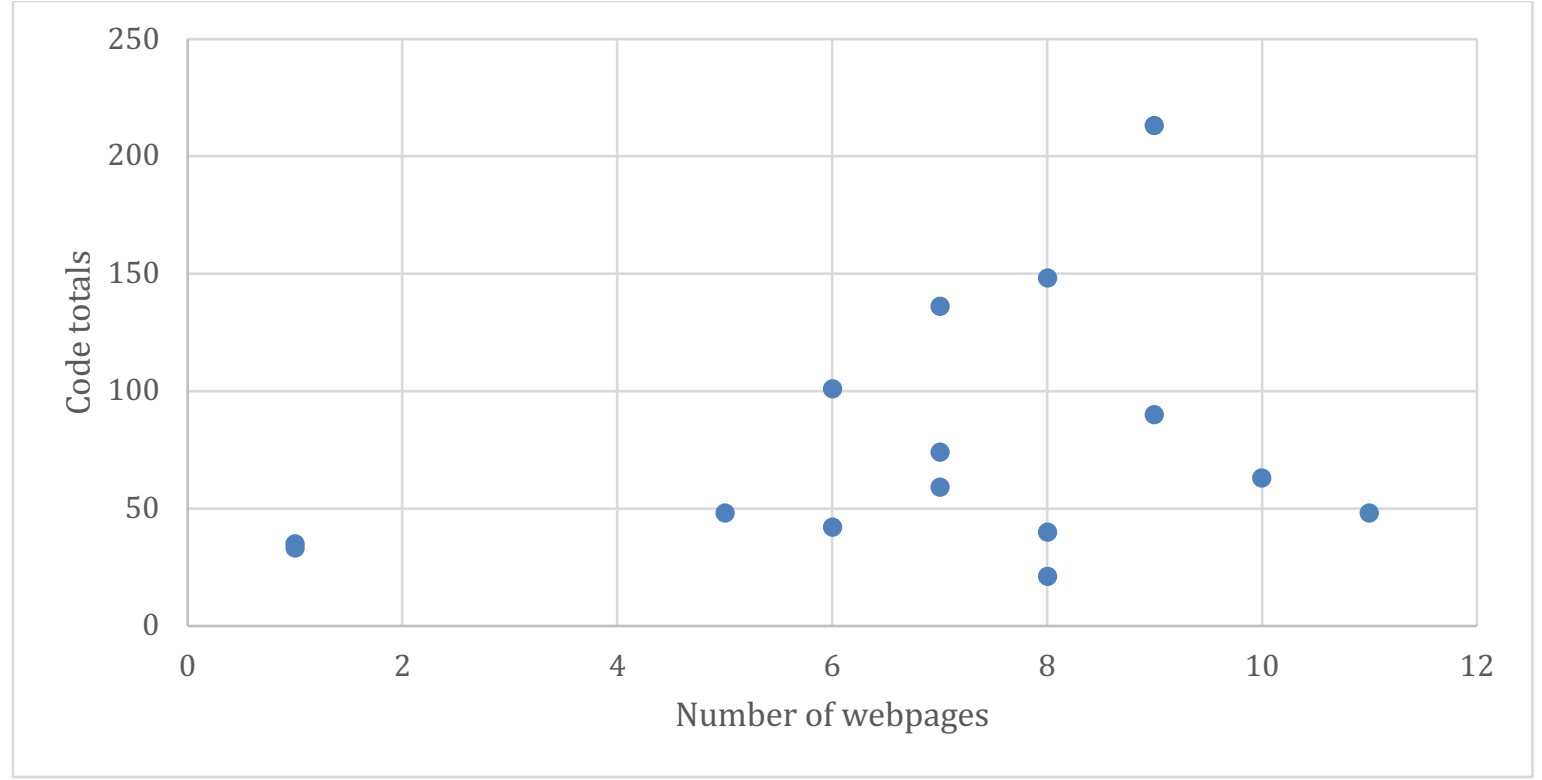

Figure 13: A scatterplot comparing the total webpages per website against the total number of codes per website.

sections (the single-page City of Boston website is an example of this) over having many shorter webpages. Thus, "webpage" as a unit of analysis is not necessarily a good measure of the amount of archaeology content.

To examine more closely how the themes were represented in each website, I plotted the actual frequencies of themes (Figure 14) and proportional representation (Figure 15). As with the websites as a whole (Table 4), Fundamental Concepts and Content are the dominant theme for most websites, with rather minimal representation of the others. When combined, this pair represented more than half of the codes for 11 of the 15 websites (AIA, Mount Vernon, SAA, and Trent University being the exceptions). 


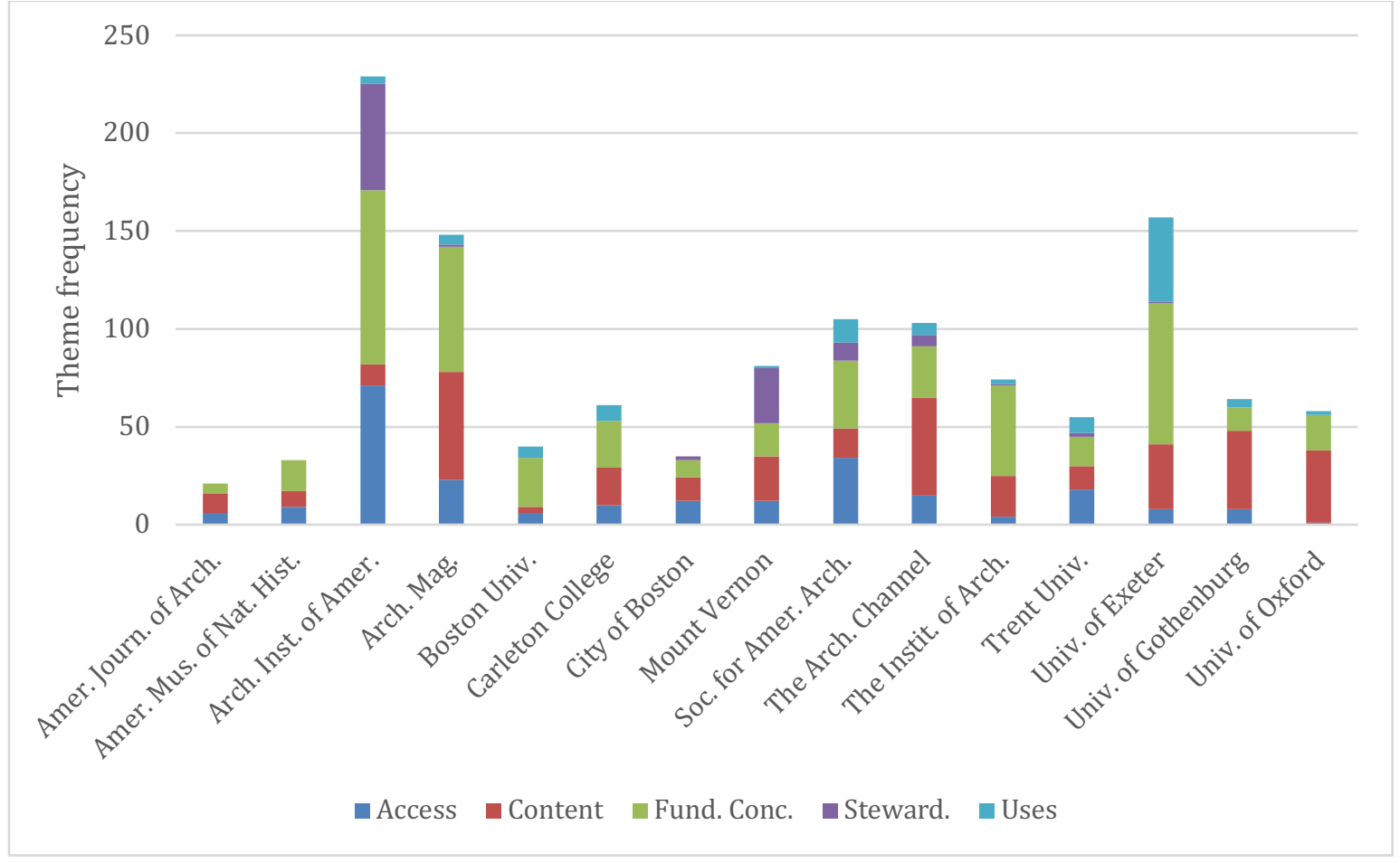

Figure 14: A stacked bar chart showing the frequency of Franklin and Moe themes illustrated by website.

Three websites broke from this pattern somewhat. The AIA and Mount Vernon websites had a high frequency of Stewardship, while the University of Exeter showed a high frequency of Uses. Just over half of the websites (eight) represented all five themes in any way, while three of them, the AIA, University of Exeter, and Archaeology Magazine conveyed multiple themes in a more robust way, however, there was still littleto-no Stewardship and Uses (Figure 14, 15).

When looking at theme distribution patterns, I noticed trends in the two least frequent themes (Stewardship and Uses), which demonstrated a limited distribution of the themes across the 15 websites (Table 4). Specifically, 74 of the 96 Stewardship codes (77\%) were from only two websites (the AIA and Mount Vernon). Mount Vernon had a "preservation" link in its top navigation, which demonstrated importance within the 
website, and the AIA addressed Stewardship across several of their webpages. Similar but less drastic, 51 of the 96 of Uses codes (53\%) were from just two websites (University of Exeter and SAA) (Table 4). The distribution of codes was more evenly distributed among websites for the other three themes.

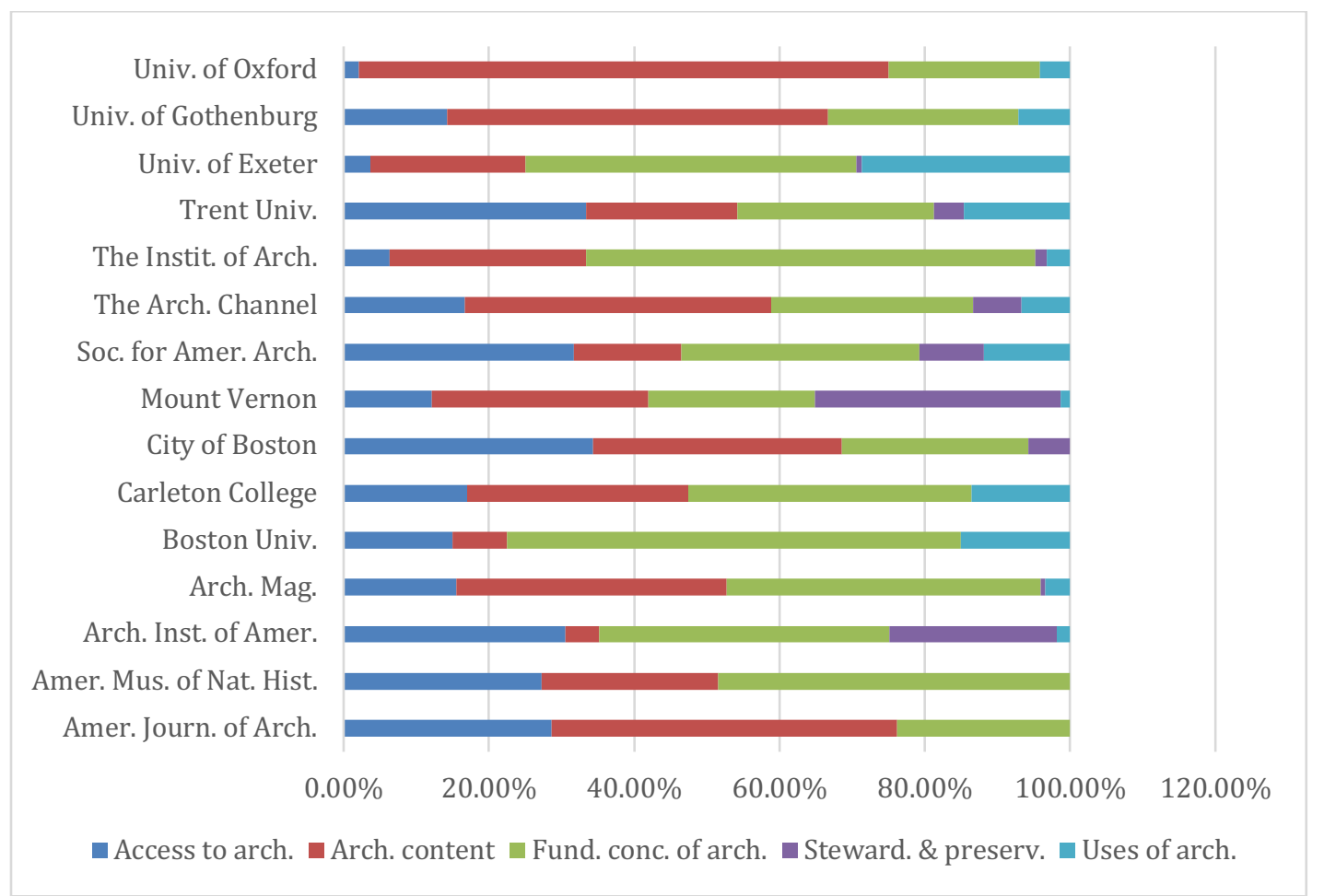

Figure 15: A stacked bar chart showing the percent of codes per theme by website.

To examine whether the frequency of themes varied depending on the type of organization supporting the website, I divided the websites into four categories: higher education; media outlet, professional organization, and publicly accessible space (Table 5). Of the seven higher education websites, only three represented all five themes (The Institute of Archaeology, Trent University and University of Exeter). The two professional organizations (SAA and AIA) did the best job of evenly representing all five 
themes. Two of the three media outlets (American Journal of Archaeology and The Archaeology Channel) had Content as their highest theme.

Table 5: The frequency of each theme by website category.

\begin{tabular}{|c|c|c|c|c|c|c|}
\hline Website & Access & Content & Fund. conc. & Steward. & Uses & Code totals \\
\hline \multicolumn{7}{|l|}{ Higher education } \\
\hline Boston Univ. & 6 & 3 & 25 & 0 & 6 & 40 \\
\hline Carleton College & 10 & 18 & 23 & 0 & 8 & 59 \\
\hline Instit. of Arch. & 4 & 17 & 39 & 1 & 2 & 63 \\
\hline Trent Univ. & 16 & 10 & 13 & 2 & 7 & 48 \\
\hline U. of Exeter & 5 & 29 & 62 & 1 & 39 & 136 \\
\hline U. of Gothenburg & 6 & 22 & 11 & 0 & 3 & 42 \\
\hline U. of Oxford & 1 & 35 & 10 & 0 & 2 & 48 \\
\hline Code totals & 48 & 134 & 183 & 4 & 67 & 436 \\
\hline \multicolumn{7}{|l|}{ Media outlet } \\
\hline Amer. Journ. of Arch. & 6 & 10 & 5 & 0 & 0 & 21 \\
\hline Arch. Channel & 15 & 38 & 25 & 6 & 6 & 90 \\
\hline Arch. Mag. & 23 & 55 & 64 & 1 & 5 & 148 \\
\hline Code totals & 44 & 103 & 94 & 7 & 11 & 259 \\
\hline \multicolumn{7}{|l|}{ Professional organization } \\
\hline Arch. Inst. of Amer. & 65 & 10 & 85 & 49 & 4 & 213 \\
\hline Soc. for Amer. Arch. & 32 & 15 & 33 & 9 & 12 & 101 \\
\hline Code totals & 97 & 25 & 118 & 58 & 16 & 314 \\
\hline \multicolumn{7}{|l|}{ Publicly accessible space } \\
\hline Amer. Mus. of Nat. Hist. & 9 & 8 & 16 & 0 & 0 & 33 \\
\hline City of Boston & 12 & 12 & 9 & 2 & 0 & 35 \\
\hline Mount Vernon & 9 & 22 & 17 & 25 & 1 & 74 \\
\hline Code totals & 30 & 42 & 42 & 27 & 1 & 142 \\
\hline
\end{tabular}

I suspect the tendency for organizational type to represent certain themes over others is linked to the mission of the organization. For example, media outlets tending to 
emphasize Content, probably reflects the fact that archaeological findings (e.g., the oldest, the most elaborate, the largest) are what media outlets perceive the public most want to learn about. The fact that the two professional organizations provided the most balanced representation of all five themes suggests that the archaeological profession accepts that the Franklin and Moe themes are what public outreach should be emphasizing. Lastly, that most of the higher education websites did not convey all five themes likely reflects institutional website structural constraints and that higher education institutions have broader educational goals outside of archaeology. This is evidenced when examining trends in theme frequency across the webpages. Of the 101 webpages coded, 14 (13.59\%) did not have a single instance of a Franklin and Moe theme (see Appendix A for code data from all webpages) and 11 of those were from higher education institutions (seven from University of Oxford alone). However, none of these 14 webpages were those specifically listed in the Google search results.

\section{What Content did the Webpages Focus On?}

Upon completing the coding of all webpages, I wanted to examine possible patterns between Franklin and Moe theme and the focus of webpage content (based on top bar navigation) for possible connections between theme presence and content focus. I went through the 103 webpages and grouped them into seven functional themes (Table 6). Nearly half (45.63\%) of the webpages were in the "programs and events" category, which had the widest range of content due to the varying nature of programs across all of the organizations. Fourteen webpages $(13.59 \%)$ were attributed to categories that may 
serve more functional purposes for the organization than archaeological purposes, specifically the "people and contacts" and "memberships and subscriptions" categories.

When looking more closely at the distribution of Franklin and Moe themes among these webpage categories (Table 7), "programs and events" accounted for $37.8 \%$ of the theme codes. A quarter of the codes $(24.5 \%)$ were from the "home pages" $(14.56 \%$ of the webpages), which could demonstrate that organizations are covering a broader range of topics on those "entry" webpages to draw people in. As in previous results, Fundamental Concepts was the most dominant theme for every webpage type, except "people and contacts," which had Content as the most frequent theme. All five themes were represented in all webpage types, except "people and contacts" (missing Stewardship) and "memberships and subscriptions" (missing Uses).

\section{Table 6: Webpage Frequency by Content Function}

\begin{tabular}{|c|c|c|}
\hline Content Function & Frequency & Description \\
\hline Programs and events & 47 & $\begin{array}{l}\text { Information about academic programs, services, event } \\
\text { listings, educational opportunities, fundraising, and other } \\
\text { ways to get involved with the organization }\end{array}$ \\
\hline Home page & 15 & $\begin{array}{l}\text { Primary webpage for an organization or department within } \\
\text { a greater organization }\end{array}$ \\
\hline Media and content & 12 & $\begin{array}{l}\text { Articles, videos, podcast episodes about the field and } \\
\text { archaeological finds }\end{array}$ \\
\hline People and contacts & 8 & $\begin{array}{l}\text { List of employees, contact information for individuals and } \\
\text { the organization }\end{array}$ \\
\hline For archaeologists & 7 & $\begin{array}{l}\text { Content, resources, and professional opportunities for } \\
\text { archaeologists }\end{array}$ \\
\hline About the organization & 6 & General information about the organization and its mission \\
\hline $\begin{array}{l}\text { Memberships and } \\
\text { subscriptions }\end{array}$ & 6 & $\begin{array}{l}\text { Information about joining an organization or subscribing } \\
\text { for additional information }\end{array}$ \\
\hline
\end{tabular}


Table 7: Franklin and Moe themes by Webpage Content Function

\begin{tabular}{lccccc|c|c}
\multicolumn{1}{c}{ Type } & Access & Content & Fund. Conc. & Steward. & Uses & Total & Pct. \\
\hline Programs and events & 79 & 97 & 168 & 47 & 44 & $\mathbf{4 3 5}$ & $\mathbf{3 7 . 8}$ \\
Home page & 49 & 82 & 115 & 12 & 24 & $\mathbf{2 8 2}$ & $\mathbf{2 4 . 5}$ \\
Media and content & 33 & 65 & 76 & 7 & 10 & $\mathbf{1 9 1}$ & $\mathbf{1 6 . 6}$ \\
For archaeologists & 33 & 19 & 38 & 13 & 2 & $\mathbf{1 0 5}$ & $\mathbf{9 . 1}$ \\
About the & 18 & 10 & 19 & 15 & 11 & $\mathbf{7 3}$ & $\mathbf{6 . 3}$ \\
organization & 2 & 28 & 9 & 0 & 4 & $\mathbf{4 3}$ & $\mathbf{3 . 7}$ \\
$\begin{array}{l}\text { People and contacts } \\
\text { Memberships and }\end{array}$ & 5 & 3 & 12 & 2 & 0 & $\mathbf{2 2}$ & $\mathbf{1 . 9}$ \\
subscriptions & $\mathbf{2 1 9}$ & $\mathbf{3 0 4}$ & $\mathbf{4 3 7}$ & $\mathbf{9 6}$ & $\mathbf{9 5}$ & $\mathbf{1 , 1 5 1}$ &
\end{tabular}

\section{Did Word Count Impact the Quantity of Archaeology Messages?}

Body text is the most dominant webpage element so I wanted to see if a higher word count on the webpages meant a higher frequency of themes (Figure 16). As discussed in the methods chapter, the segment of "body text" could be a word, phrase, sentence, or two-to-three sentences to capture enough context. There was a weak relationship between "body text" and webpage wordcount (Figure 16). Perhaps not surprisingly, this means that having a higher word count on a webpage does not automatically lead to more archaeology messages. 


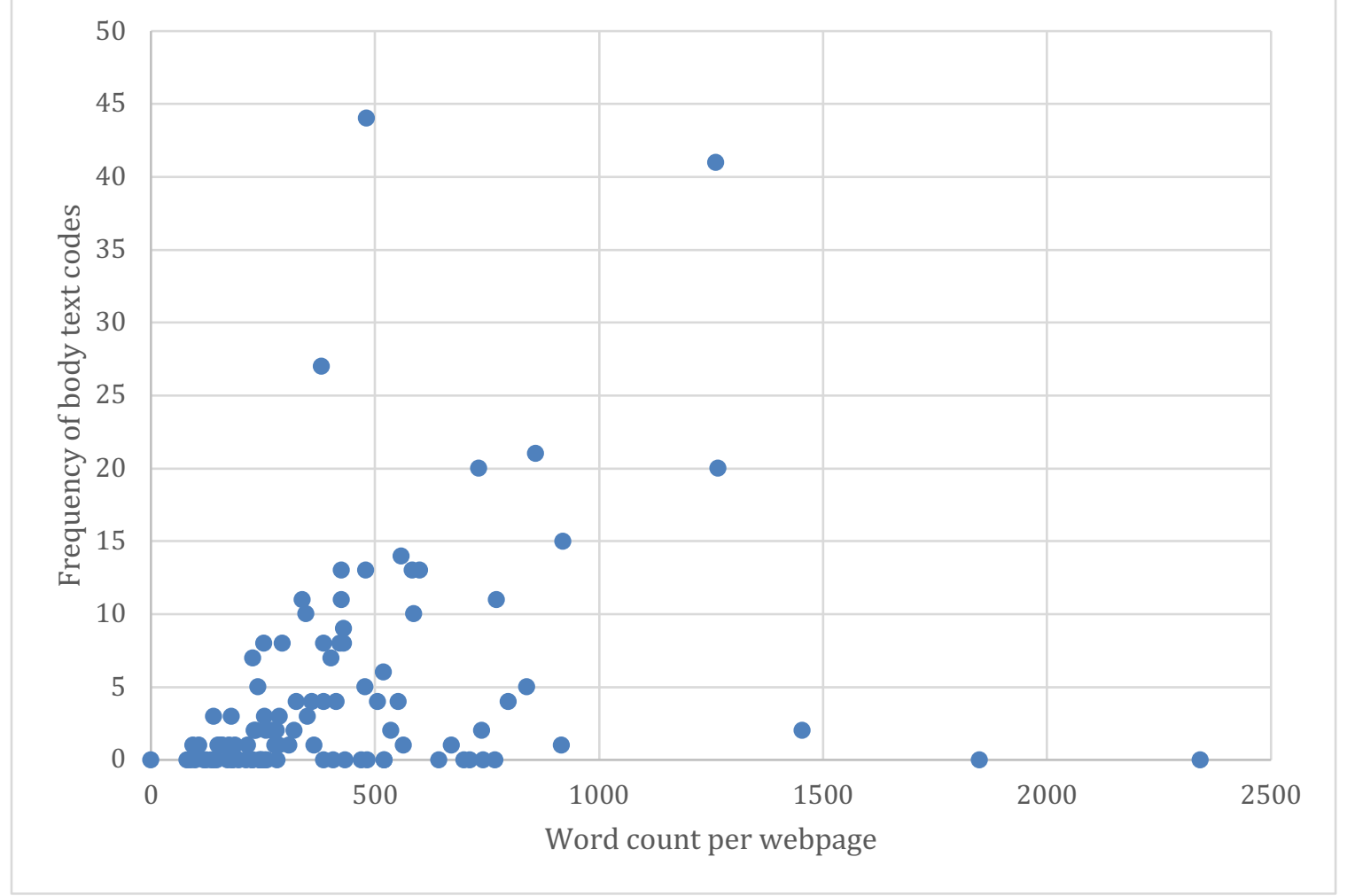

Figure 16: A scatterplot comparing frequency of body text codes to word count of each webpage.

\section{What are Good Examples of Each Franklin and Moe Theme?}

As part of my webpage analysis, I wanted to highlight some exemplary examples of how organizations demonstrated the Franklin and Moe themes to show how these ideals could be conveyed with intentionality when creating website content. I used a variety of criteria to select the quotations for each theme: 1) the theme was expressed explicitly without requiring the visitor to explore the full webpage or more of the website to understand it, 2) text written in plain language, 3) high quality photos in composition and resolution, 4) "call to actions" that invite the visitor to engage (e.g., read more, click on a link, watch a video, sign up for something, take action), 5) conveying multiple 
Franklin and Moe themes in one quotation, and 6) incorporating contemporary archaeology issues and areas of focus (e.g., social justice).

There were limited examples I could select from with Uses and Stewardship. I have organized the examples below in order of least frequent to most frequent theme. Uses of Archaeology

Uses was illustrated to a very limited degree (only 95 of 1,151 theme codes) and three websites had no examples of this theme at all. As explained previously, Uses was conveyed on the webpages including through descriptions of how to use archaeology degrees and minors in other career fields, lists of archaeology career paths, employee biographies explaining their education and career backgrounds, statements about using archaeology to support social justice, higher education course description and titles, or descriptions of archaeology projects with goals to learn about marginalized populations.

Of the examples available, two illustrate how website content can highlight Uses (Figures 17-18). In several instances, higher education institutions pointed visitors toward ways archaeology courses and degrees could be used in other fields. Carleton College's "Home" webpage (Figure 17) explicitly listed degree programs that were supported by taking archaeology classes, which would be a simple way for higher education institutions to include Uses in their website content. There were few instances where archaeology was shown as contributing to contemporary issues such as climate change or social justice. One example, though limited, was Mount Vernon's "Archaeology Home" webpage (Figure 18). This features a text box related to records of slavery, which is an example of archaeology being used to give voice to marginalized parts of society, broadly supporting social justice at a specific location. 


\section{Archaeology concentrators since 1991 have majored in: Studio Art, Art History, Biology, Chemistry, Classical Languages, Geology, History, Political Science, Psychology, Religion, and Sociology and Anthropology.}

Figure 17: Carleton College's "Home" webpage listed degree programs that are supported through archaeological study (Uses).

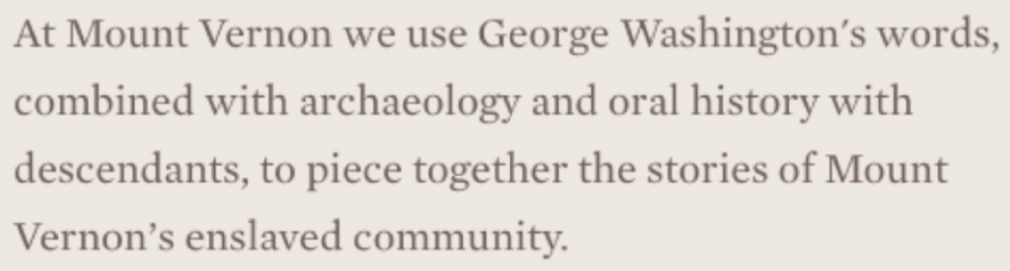

Figure 18: Mount Vernon's “Archaeology home” webpage had a sentence that connected archaeology to a social justice issue (Uses).

\section{Stewardship and Preservation}

Stewardship was illustrated to a very limited degree (only 96 of 1,151 theme codes) and six websites were lacking examples of this theme entirely. Stewardship quotations included descriptions of preservation programs and funding opportunities, organizational mission statements supporting preservation, photos and descriptions of conservation activities, field work opportunities with a conservation focus, descriptions of threats to archaeological sites, description of laws and regulations supporting stewardship, lists of ways individuals can participate in preservation, invitations to provide feedback on legal issues, and more.

Like Uses, Stewardship had very few examples overall to select from. Two examples from AIA’s “Site Preservation” webpage (Figures 19-20) illustrate interesting ways Stewardship can be expressed on archaeology websites. Figure 19 highlighted an interactive opportunity to learn about Stewardship by taking a quiz. Figure 20 was an 
infographic with facts about the importance and impact of site preservation, which is a good way to show brief details to an audience learning about a new topic or seeking some statistics they can share with others.

\section{Preservation Quiz}

Figure 19: Mount Vernon's "Preservation" webpage included an interactive opportunity to engage by taking a quiz (Stewardship). 


\section{Archaeological Institute of America}

\section{Site Preservation BY THE NUMBERS}

The AIA Site Preservation Program provides grants of up to $\$ 25,000$ to innovative projects that preserve archaeological sites

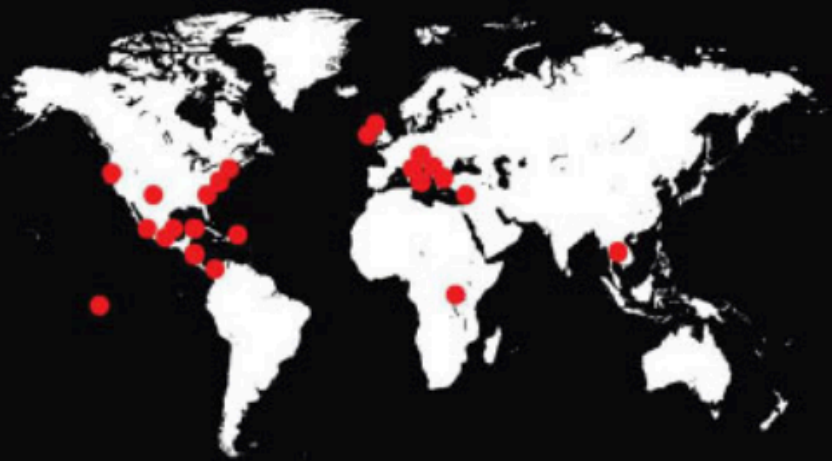

26 Projects funded worldwide

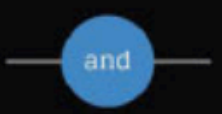

$\$ 604,885$

distributed in grants and awards since 2008

Facts and Figures from 8 AIA-supported projects:

Read more about all of our projects at archaeoloeical.org/sitepreservation
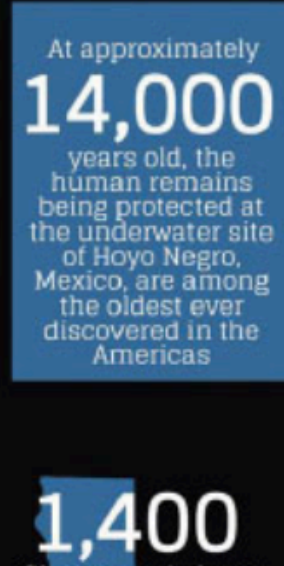

Site stewards have beenitrained by the Galitornia

Archaeology site

Stewardship Program since 1999
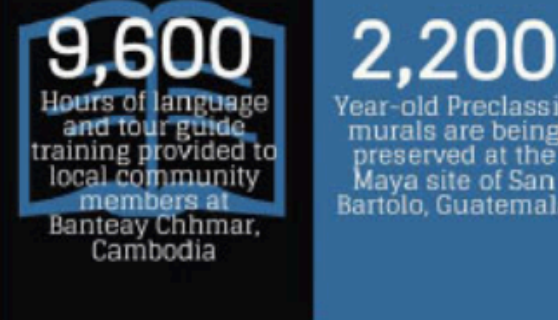

Year-old Preclassic murals are being preserved at the pava site of San Bartolo, Guatemala
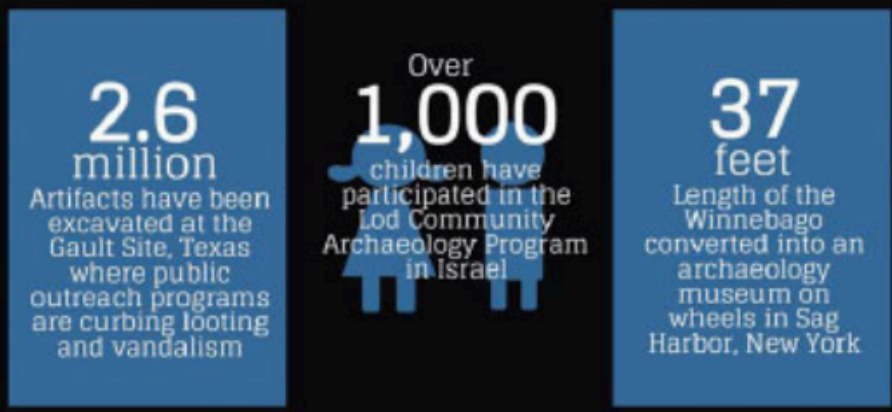

Make your gift at archaeological.org/sitepreservation/donate

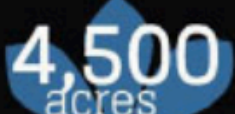

deres

Area ot the biocultural reserve created around the site of Kaxil Kiuic, Mexico

feet

Winnebago

Werted into an

wheels in 5 .

Harbor, New York

Figure 20: The AIA's "Site Preservation" webpage had an infographic about site preservation (Stewardship). 
Access to Archaeology

Access, moderately frequent, occurred 219 of the 1,151 theme instances. The quotations from this theme included invitations to subscribe to magazines and newsletters, listings of archaeology events, the word "collaboration" as a link name, information on how to access resources/libraries/labs, scholarships and funding opportunities, information about archaeology publications, hands-on archaeology opportunities, digital and interactive archaeological learning, social media links for an organization, and more.

Two examples illustrate the power of websites to convey Access (Figures 21-22). Mount Vernon's “The Estate” webpage (Figure 21) features a large photograph of the big house and used digital technologies to invite people to tour the location without having to travel there in person, which made Mount Vernon accessible to a global audience. Archaeology Magazine's "Home" webpage had a graphic for Crow Canyon Archaeological Center (Figure 22). This is a good example of Access because it uses compelling images and text to let webpage visitors know that the center exists, the type of experiences available there, and it also conveys Content because it is about a specific archaeological site. 


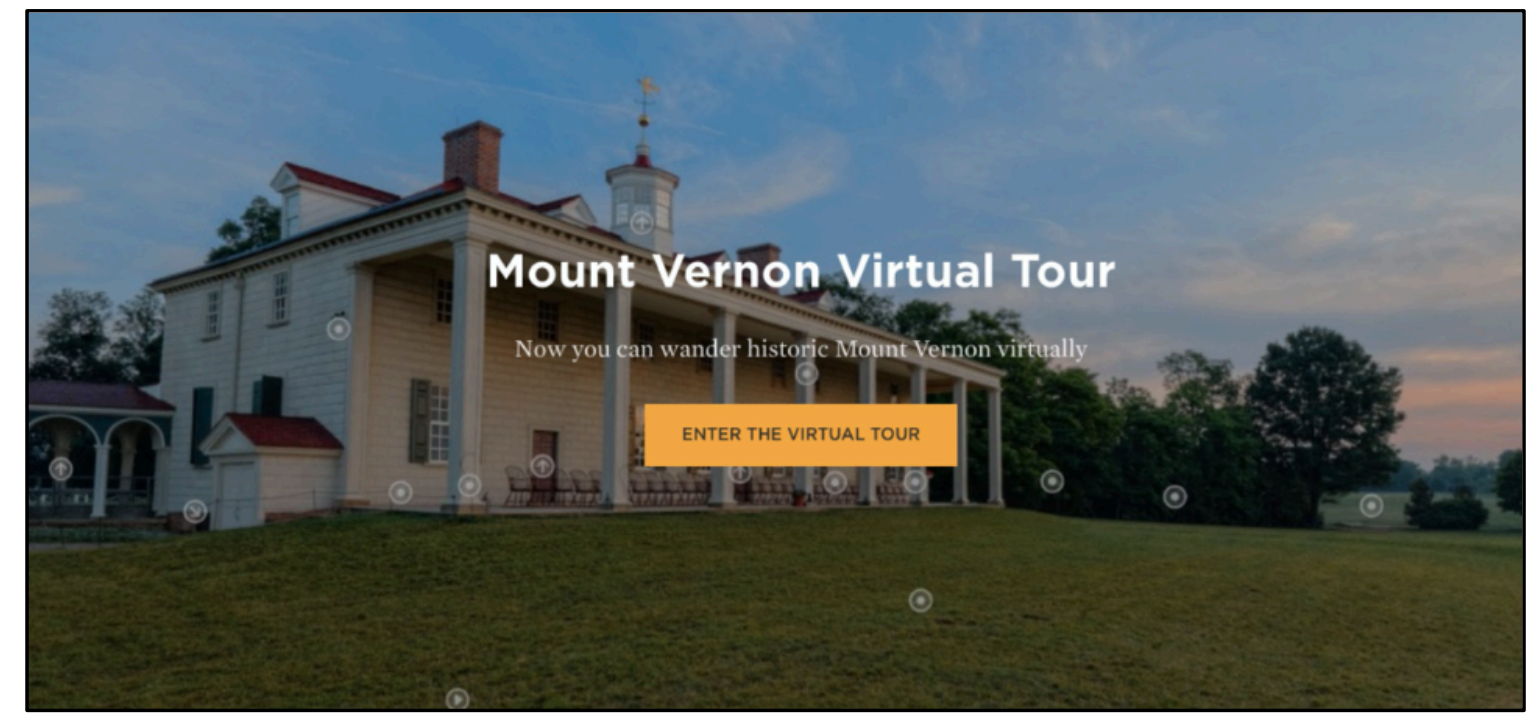

Figure 21: An image from Mount Vernon's "The Estate" webpage inviting people to participate in a virtual tour (Access).

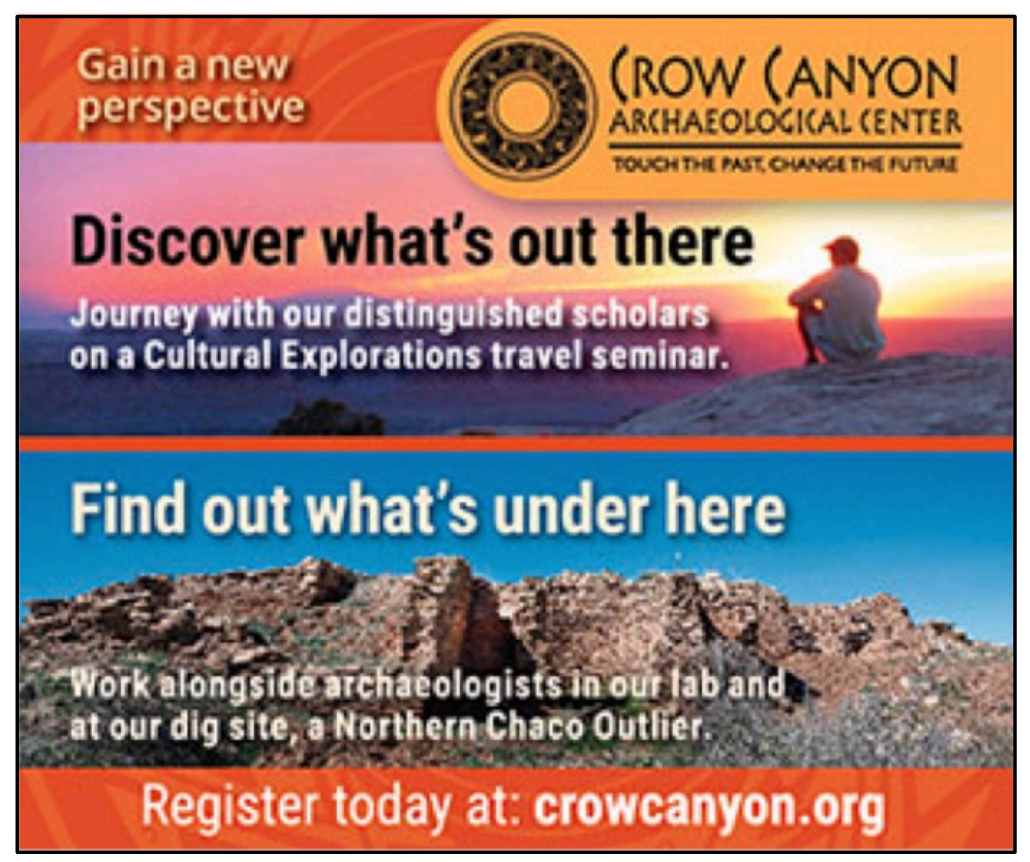

Figure 22: Archaeology Magazine's "Home" webpage includes this graphic advertisement for Crow Canyon Archaeological Center (Access). 


\section{Archaeological Content}

Webpages largely focused on Content as it was the second most-frequent theme at 304 instances. The Content quotations included headlines and articles about archaeological discoveries, descriptions about archaeology projects, description of research and faculty focus areas, academic course titles and descriptions, description of artifacts, maps/drawings/photos from archaeological sites, funding opportunities for projects connected to specific locations and time periods, virtual tours of archaeological sites and artifacts, and more.

Of the Content quotations, two examples (Figures 23-24) stood out in showing how Content could be conveyed on archaeology websites. Mount Vernon's “Archaeology Home" webpage (Figure 23) used a strong image, text, and call to action (i.e., "learn more" button) to engage website visitors. This example also pulled in two other themes: Fundamental Concepts by mentioning surveying as a methodology and Uses by conveying how archaeology can be used in social justice, specifically African American history. Also, the City of Boston's "Home" webpage (Figure 24) shows how to use wellwritten and concise copy to encourage people to watch a video, which is likely more effective than simply sharing a video without any call to action. 


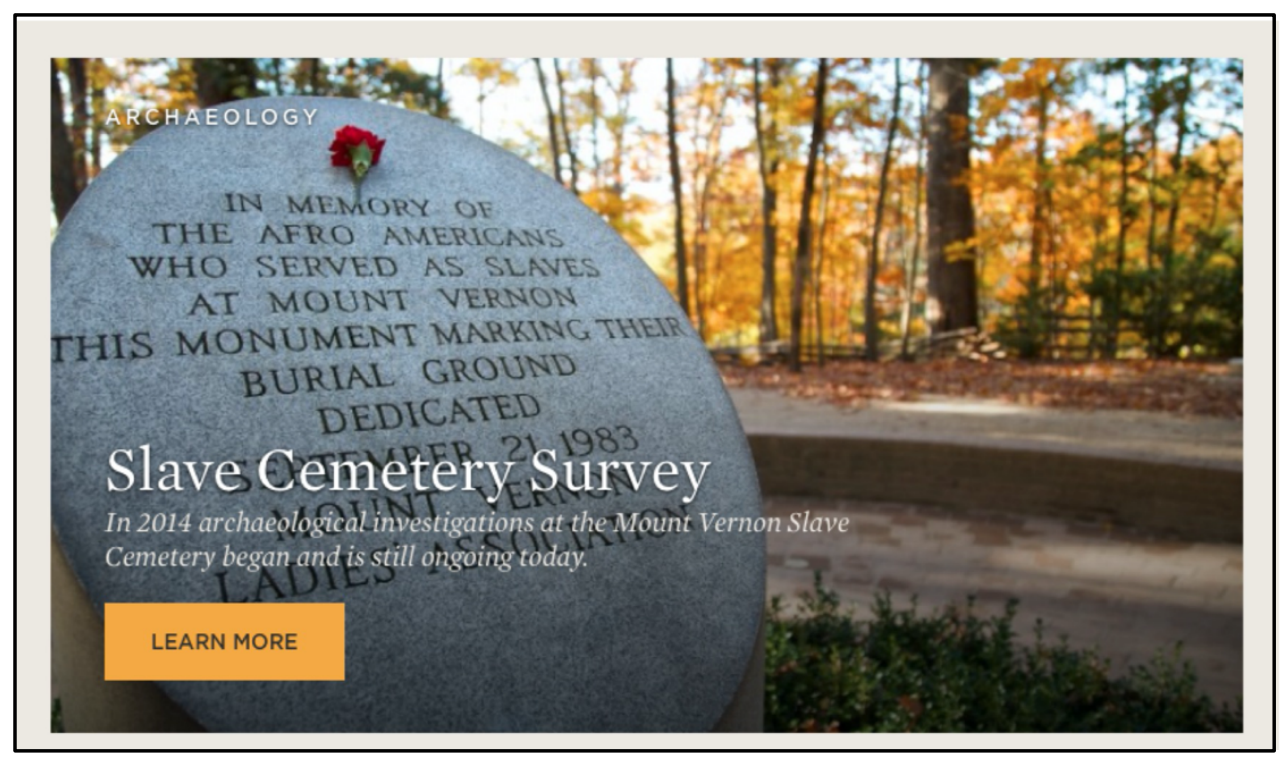

Figure 23: An example from Mount Vernon's “Archaeology Home” webpage that uses a strong image, text and call to action (Content).

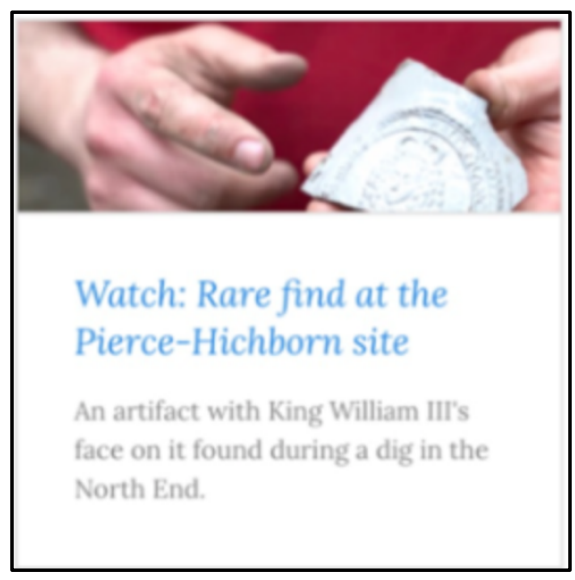

Figure 24: City of Boston's "Home" webpage uses video and a call to action with image and text (Content).

Fundamental Concepts of Archaeology 
The most frequent theme at 437 instances, Fundamental Concepts was conveyed on the archaeology webpages in multiple ways including, providing definitions of archaeology, description of methods and labs, images and videos of field work/lab work/artifacts, lists of archaeology specializations and subfields, archaeology course descriptions, lists of research projects and foci among organizations and its staff, and descriptions of organizations and their missions.

With such a high frequency of this theme, I had many examples to choose from. I selected two quotations (Figures 25-26) to demonstrate effective ways website creators could represent Fundamental Concepts. The University of Exeter used a video on their "Fieldwork" webpage (Figure 25), which conveyed field work as an important part of Fundamental Concepts. The City of Boston's “Home” webpage (Figure 26) included a strong example of how their website visitors could learn a great deal about archaeological excavation through content detailing an excavation from start to finish. Also, the photo of artifacts both shows some of what could be found in the city as well as being visually engaging.

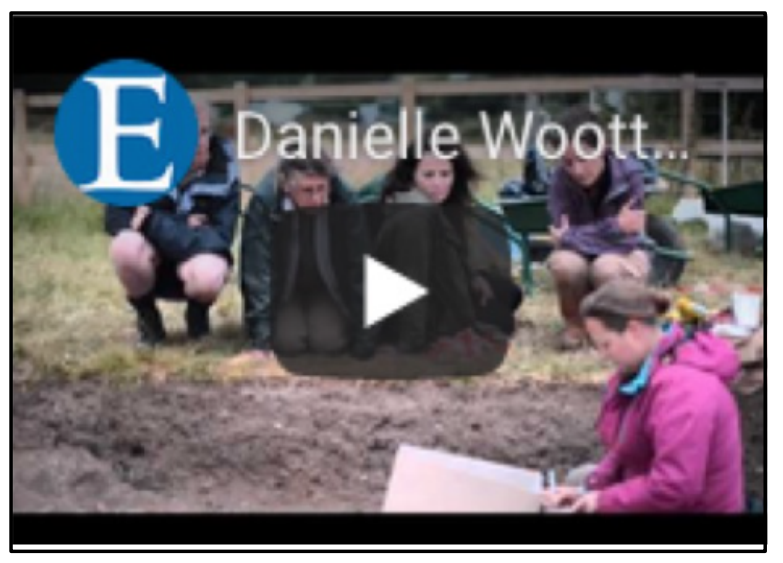

Figure 25: University of Exeter's "Fieldwork" webpage used video to show fieldwork (Fundamental Concepts). 


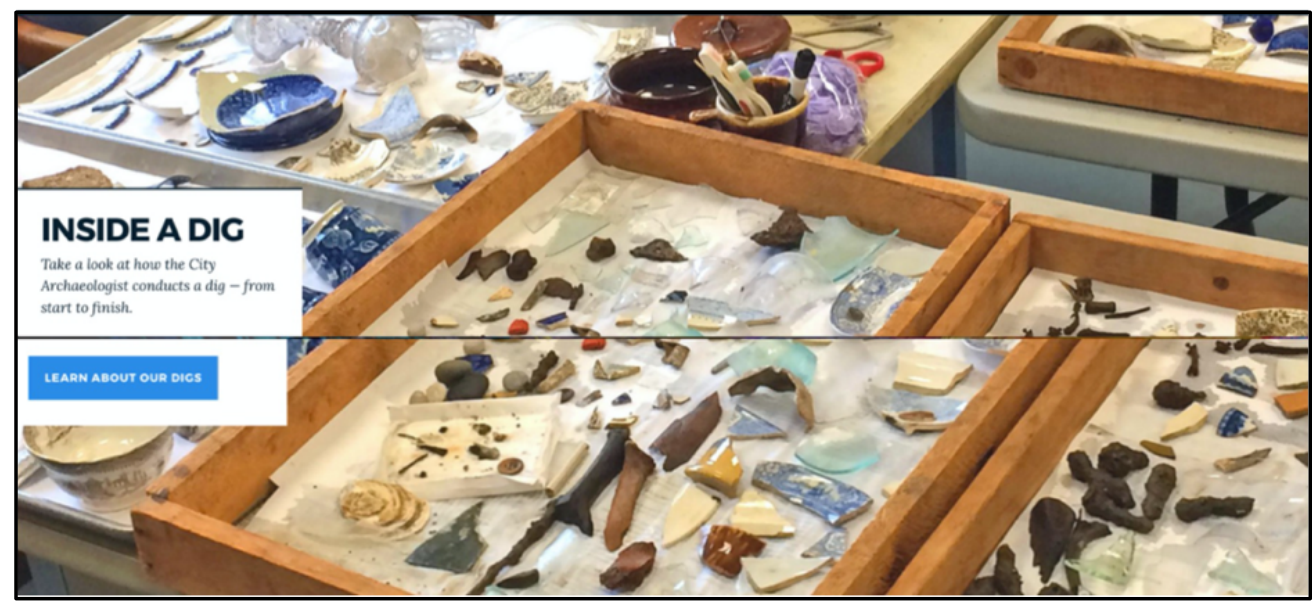

Figure 26: City of Boston's "Home" webpage had information about how archaeology excavations are conducted and shows a collection of artifacts (Fundamental Concepts). 


\section{Chapter 5: Discussion and Conclusions}

Archaeology has seen an increase in public archaeology assessment in the past five years or so, however, most of this work has focused on in-person activities with little on digital public archaeology assessment (Bartoy 2012, Bollwerk 2015, Ellenberger and Richardson 2018, Franklin and Moe 2012, King 2016, Richardson and Almansa-Sánchez 2015). Given the massive popularity of websites as a digital media and a useful tool for archaeologists (Childs 2002, Goskar 2012, Limp 2011, Lock 2006, McDavid 2004, Richardson 2013), it is critical that we thoughtfully and consistently assess our public archaeology efforts in digital spaces. This assessment could be a significant step toward creating an archaeologically literate public by understanding the information archaeologists are distributing on websites.

My thesis project contributed to this call for more public archaeology assessment by evaluating whether QCA serves as an effective approach to assessing archaeology websites. To achieve this, I tested whether Franklin and Moe's (2012) five themes of archaeological literacy could be a useful framework for QCA assessment on websites by coding their presence on 15 archaeology websites (103 webpages). To my knowledge this is the first study using QCA to assess archaeology websites.

\section{Was QCA a Good Assessment Tool?}

Qualitative Content Analysis was an effective tool to assess messages on archaeology websites for several reasons. It allowed me to see the extent and presence of the Franklin and Moe themes, which showed that Stewardship and Uses were rarely featured on websites. The themes were a good framework for QCA as evidenced both by my high 
intracoder reliability and that all content I wanted to code fit in the themes. I believe part of the themes' usefulness came from their being general enough yet distinctive in meaning to be applicable to websites from a variety of organizations.

Procedurally, QCA allowed me to systematically comb through all content on a webpage; a task that would have been much more nebulous without such a tool. The sampling methodology I used produced a robust sample of websites and allowed me to assess a consistent sample of webpages among them. Also, I found that my record creation process was effective as it allowed me to have a static version of each webpage that could not be affected by possible updates to the websites and it worked well for coding within ATLAS.ti. Lastly, ATLAS.ti was a functional and useful computer-assisted qualitative data analysis tool that allowed me to conduct the assessment I had planned for this study. I invested 20-25 hours in learning how to use the software through in-person training and online tutorials. The webpage coding itself took only 10 hours, which is a modest outlay of time given the insights provided.

Though QCA was extremely useful for this project, there were a few challenges to the process. It was difficult to differentiate between the text-based webpage elements (i.e., headline, caption, subhead, link name, body text) due to the widely inconsistent formatting styles across webpages. If I were to start this coding process again, I would consider re-working the text webpage elements to code for text length instead of (or in addition to) style. For example, I would want to know whether the quotation was from a paragraph/block of text, a short phrase (e.g., bullet points), or a label (e.g., a word or two that was clickable). This would have allowed me to explore whether the placement of archaeology messages coincides with research showing how people tend to explore a 
webpage. Lastly, I experienced a fairly significant learning curve with ATLAS.ti and I recommend seeking out in-person and digital training resources.

Considering all of this and my results, I believe that my implementation of QCA on the 15 archaeology websites was consistent and reliable. The five Franklin and Moe themes were straightforward, and I believe other archaeologists could follow this methodology that would produce similar results demonstrating a high use of Fundamental Concepts and Content and a low use of Stewardship and Uses on these 15 websites. However, if a project were to assess more abstract themes (e.g., co-creation of knowledge, decolonizing archaeology), it would be important to have multiple coders to ensure consistent coding of more complicated topics and that the definitions used for such themes are representative of multiple perspectives.

\section{What Messages are Missing from the Most Popular Archaeology Websites?}

The results of my study indicate that archaeology websites hardly consider Stewardship and Uses (96 and 95 theme frequency, respectively, out of 1,151). Seven of the 15 websites lacked examples of one or both of these themes. Fundamental Concepts (437), Content (304), and to some extent Access (219), dominated the messages on the most popular websites the public visits. This trend is concerning.

Stewardship has been a central focus of archaeology for decades (Lipe 1974, Wylie 1999). It is a fundamental part of Cultural Resource Management (Little 2012) and is central or woven into the code of ethics for numerous professional archaeology associations (e.g., SAA, AIA, World Archaeology Congress, European Association of Archaeologists). The content on archaeology websites is not supporting that focus. We 
need to do better by demonstrating the value of conserving the archaeological record and explicitly telling people how they can participate in that process.

Uses is an important part of public archaeology because it demonstrates to groups (e.g., local communities, government agencies, funding organizations) that archaeology is relevant to contemporary issues like racism and social justice (McDavid 2007, Mullins 2007, Shackel 2007, Little and Shackel 2014), climate change (Hardesty and Little 2009), garbage and waste (Rathje 2002), intellectual property rights (Atalay 2012), immigration (Crist 2002), and migration (Little 2012). It is not enough to talk about these benefits of archaeology primarily in traditional publishing spaces. We must tout these benefits on digital media so the public and other stakeholders can understand the direct and significant impact archaeology can make to our everyday lives. We have to inspire the public to see these benefits; website content can play an important role here.

I believe one challenge archaeologists face in representing Stewardship and Uses is the difficultly in conveying them in a visual format. Websites make great use of images and archaeologists are encouraged to use images to tell archaeological stories (Connah 2010, Fagan 2010, Zimmerman 2003). However, Stewardship and Uses do not lend themselves to visual representations as easily as the themes of Fundamental Concepts and Content that can be presented through images of archaeological sites and artifacts. By being intentional with conveying Stewardship and Uses through "body text" and "photos" (the two most popular webpage elements), archaeologists could significantly increase the presence of these important themes.

Stepping outside of the 15 websites assessed in this study, I searched Google for "archaeology stewardship" and "uses of archaeology" to identify examples that illustrate 
these themes well. The Colorado Archaeology Society, Pikes Peak Chapter (coloradospringsarchaeology.org/stewardship/), had a list of practical stewardship actions, such as "put artifacts back where they are found" and this "don't":

"Camp on archaeological sites. Food attracts rodents who may then nest in the site, smoke damages rock art, and the introduction of modern charcoal from campfires precludes the ability to radiocarbon date a site at a later time."

With Uses, a particularly good example was from the Pennsylvania Historical \& Museum Commission (phmc.state.pa.us/portal/communities/archaeology/resources/value-archaeology.html). The website directly addressed that people may primarily associate archaeology with photos of ancient ruins and artifacts, but that archaeology is an important part of the past for every person and society that has relevance to us today. The webpage went on to describe why archaeology is important and how archaeologists examine and care for the past. This webpage used a mix of images and body text, with easily scannable sections using subheads, to address several themes and the importance of archaeology today.

To help archaeologists better and more intentionally incorporate the Franklin and Moe themes into website content, I have listed the traits of each theme and ideas of how to demonstrate them (Table 8). This could be helpful to website managers who identify missing or minimally represented themes on their website. 
Table 8: Traits of the Franklin and Moe (2012) Themes and Possible Ways to Demonstrate Them in Digital Media

\begin{tabular}{|c|c|c|}
\hline Theme & Theme Traits & Ideas for Conveying Theme \\
\hline Access & $\begin{array}{l}\text { - Multivocality } \\
\text { - Engaging the public in archaeology } \\
\text { - Participatory archaeology }\end{array}$ & $\begin{array}{l}\text { - Interview with tribal representative about } \\
\text { cultural context of findings } \\
\text { - Links to social media accounts } \\
\text { - Field school information } \\
\text { - In-person and online event details } \\
\text { - Opportunities to communicate directly with } \\
\text { an archaeologist } \\
\text { - Virtual tours of sites }\end{array}$ \\
\hline Content & $\begin{array}{l}\text { - History of archaeology } \\
\text { - Significant archaeological sites } \\
\text { - Significant archaeological debates } \\
\text { - Results of archaeological work } \\
\text { - Interpretations about past people }\end{array}$ & $\begin{array}{l}\text { - Timeline of occupation at a site/region } \\
\text { - Interview with archaeologist about findings } \\
\text { - Blog posts about daily life of past people at } \\
\text { the site }\end{array}$ \\
\hline $\begin{array}{l}\text { Fund. } \\
\text { Conc. }\end{array}$ & $\begin{array}{l}\text { - How archaeologists construct } \\
\text { knowledge } \\
\text { - Importance of context } \\
\text { - Archaeology methods } \\
\text { - Terminology }\end{array}$ & $\begin{array}{l}\text { - Artifact photos and illustrations } \\
\text { - Video demonstration of how particular } \\
\text { analyses directly lead to insights (e.g. } \\
\text { comparing fragmentary ceramics or animal } \\
\text { bones to complete specimens) } \\
\text { - Frequently asked questions about the } \\
\text { methods used in a project }\end{array}$ \\
\hline Steward. & $\begin{array}{l}\text { - What is lost through site destruction } \\
\text { - Value of context } \\
\text { - Preservation laws } \\
\text { - Protection of heritage }\end{array}$ & $\begin{array}{l}\text { - Ways the public can avoid damaging a site } \\
\text { - Personal reflections from Indigenous people } \\
\text { about what is harmed when sites are } \\
\text { disturbed } \\
\text { - Infographic of how the public can help } \\
\text { preserve sites } \\
\text { - Describing associated programs and } \\
\text { organizations } \\
\text { - Video showing how to identify an } \\
\text { archaeology site } \\
\text { - Statement of conservation ideals }\end{array}$ \\
\hline Uses & $\begin{array}{l}\text { - Teach critical thinking and problem- } \\
\text { solving } \\
\text { - Teach science with culturally } \\
\text { relevant information } \\
\text { - Improve cultural understanding } \\
\text { - Help people connect to their heritage } \\
\text { - Promote diversity and social justice }\end{array}$ & $\begin{array}{l}\text { - Academic course and program descriptions } \\
\text { detailing connections to other fields } \\
\text { - Details of projects using archaeology to } \\
\text { address contemporary issues } \\
\text { - Descriptions of social justice activities an } \\
\text { organization is participating in }\end{array}$ \\
\hline
\end{tabular}


Future Work

QCA is an effective tool for assessing archaeology content in digital media and there are many possibilities for future work in this area. One focus could be on additional themes than were offered by Franklin and Moe that could be assessed with tools such as QCA, surveys, and interviews. Since 2012, when Franklin and Moe published their paper and I started this project, additional themes have grown in prominence within professional archaeology, such as co-creation and decolonizing archaeology (Atalay 2012, Bollwerk 2015). If our discipline embraces their importance, archaeologists need to be communicating them to the public, to broaden the definition of literacy as set by Franklin and Moe (2012).

Future work could expand the use of QCA to assess archaeology messages (the Franklin and Moe themes and beyond) on social media platforms or blogs instead of websites (Bollwerk 2015, Kelpšienė 2019, Rodríguez Temiño and González Acuña 2014, Walker 2014a). One could look at content and engagement on spaces such as Facebook pages, Instagram profiles, Facebook groups, and Twitter profiles. It could also be beneficial to compare content type (e.g., photos, videos, links, text) containing archaeology messages against posts with the most engagement to determine not only what kinds of archaeology messages are being shared, but which ones are deemed the most engaging by the viewers.

Aside from use of QCA on static messages, other approaches to archaeology website assessment could involve the end-users. Depending on an organization's resources, this could be done through strategies such as focus groups, brief survey popups on the website, or user experience testing to understand how people use the websites 
and what they are learning from them. QCA could be applied to survey results and transcripts from focus groups and interviews. One could use an approach like Geralyn Ducady et. al. (2016) and apply assessment before and after users engage with a website to understand if their understanding of archaeology changed as a result of what they experienced. As archaeology incorporates more collaborative and "horizontal" approaches, work in this area would be valuable.

In addition to understanding what visitors are learning from websites, one could work directly with website creators to discover what messages they are intending to convey. This approach could involve asking website creators about their website goals and comparing those to results from a QCA assessment of archaeology messages on the websites. It would also be valuable to gain access to the Google Analytics for a website to understand traffic as a way to identify popular webpages to evaluate.

I would also like to see tools developed to help archaeology website creators build more effective websites, such as help in developing website objectives, creating intentional and effective content, and providing assessment tools to help them determine whether their websites are achieving their goals. A combination of working with website creators and end users could allow researchers to understand whether the website visitors are getting from archaeology websites what their creators intended, and how the websites are affecting the public's understanding of archaeological themes.

\section{Conclusions}

Websites will continue to grow as an important way for archaeologists to engage the public. Given their prominence and the importance of assessment in general, website 
assessment clearly deserves more scholarship. Not only do we need to critically evaluate what we are communicating through websites and social media platforms, we need methods for conducting such assessment. Supporting this work could involve analysis of ways other fields use QCA as well as other website assessment options to identify the most effective approaches for archaeologists.

In addition to assessing the content we are sharing with the public, we need to be more intentional when creating it. As intentional as archaeologists are with messages in scholarship, educational programs, and in-person public archaeology events, the same care should be applied to website and social media content as those media have the potential for reaching a much larger audience than traditional forms of academic information sharing.

The opportunity to engage the public in archaeology becomes increasingly important as budgets and resources become scarcer, particularly given what we have experienced during the COVID-19 pandemic. As our global community adjusts to changing circumstances through the years to come, digital platforms will become even more important.

Not only do archaeologists need to find new and engaging communication tools to meet the public where they are, archaeologists must be more deliberate about assessing use of those tools. By providing a relatively easy and explicit approach to assessing archaeology websites, this study makes an important contribution to digital public archaeology assessment and understanding what archaeologists are communicating to the public. 


\section{References cited}

Ackland, Robert

2013 Web Social Science: Concepts, Data and Tools for Social Scientists in the

Digital Age. SAGE: Los Angeles.

Altheide, David L. and Christopher J. Schneider

2013 Qualitative Media Analysis. SAGE: Los Angeles.

Apaydin, Veysel

2016 Effective or Not? Success or Failure? Assessing Heritage and

Archaeological Education Programmes - the Case of Çatalhöyük

Atalay, Sonya

2012 Community-Based Archaeology: Research with, by, and for Indigenous and Local Communities. University of California Press: Berkeley.

Bartoy, Kevin M.

2012 Teaching through Rather than About: Education in the Context of Public Archaeology. In The Oxford Handbook of Public Archaeology, edited by Skeates, Robin, Carol McDavid and John Carman. Oxford University Press: Oxford, 552-565.

Black, Paul and Dylan Wiliam

1998 Inside the Black Box: Raising Standards through Classroom Assessment:

Formative Assessment is an Essential Component of Classroom Work and can Raise Student Achievement. Phi Delta Kappan 92(1).

Bollwerk, Elizabeth

2015 Co-Creation's Role in Digital Public Archaeology. Advances in Archaeological Practice 3(3):223-234.

Childs, S. Terry

2002 The Web of Archaeology: Its Many Values and Opportunities. In Public

Benefits of Archaeology, pp. 228-238. University Press of Florida:

Gainesville.

Colombo, Cinzia, Graziella Filippini, Anneliese Synnot, Sophie Hill, Roberta Guglielmino, Silvia Traversa, Paolo Confalonieri, Paola Mosconi and Irene Tramacere

2016 Development and Assessment of a Website Presenting Evidence-Based Information for People with Multiple Sclerosis: the IN-DEEP Project. BMC Neurology 16(30): 1-9.

Connah, Graham 2010 Writing about Archaeology. Cambridge University Press: Cambridge. 
Crist, Thomas A.

2002 Empowerment, Ecology, and Evidence: The Relevance of Mortuary Archaeology to the Public. In Public Benefits of Archaeology, edited by Little, Barbara J. University Press of Florida: Gainesville, pp. 101-117.

Dixson, Dante D. and Frank C. Worrell

2016 Formative and Summative Assessment in the Classroom. Theory Into Practice 55(2): 153-159.

Ducady, Garalyn, Mariani Lefas-Tetenes, Sarah Sharpe, and Miriam A. W. Rothenbergy 2016 Archaeology and the Common Core. Advances in Archaeological Practice 4(4): 517-536.

Ebbeck, Marjory, Geraldine Lian Choo Teo, Cynthia Tan, and Mandy Goh 2014 Relooking Assessment: A Study on Assessing Developmental Learning Outcomes in Toddlers. Early Childhood Education Journal 42: 115-123.

Ellenberger, Kate and Lorna-Jane Richardson

2018 Reflecting on Evaluation in Public Archaeology. Online Journal in Public Archaeology 8: 65-94.

Elo, Satu and Helvi Kyngäs

2008 The Qualitative Content Analysis Process. Journal of Advanced Nursing 62(1):107-115.

Fagan, Brian M.

2010 Writing Archaeology: Telling Stories about the Past. Left Coast Press: Walnut Creek.

Franklin, M. Elaine and Jeanne M. Moe

2012 A Vision for Archaeological Literacy. In The Oxford Handbook of Public Archaeology, edited by Skeates, Robin, Carol McDavid and John Carman. Oxford University Press: Oxford, 566-580.

The Friends of Çatalhöyük

2014 Çatalhöyük: Excavations of a Neolithic Anatolian Höyük. Electronic document, http://www.catalhoyuk.com, accessed Nov. 11, 2014.

Fritz, John M. and Fred T. Plog

1970 The Nature of Archaeological Explanation. American Antiquity 35(4):405412.

Gibbs, Graham

2014 Using Software in Qualitative Analysis. In The SAGE Handbook of

Qualitative Data Analysis, ed. Uwe Flick, pp. 277-294. 
Given, Lisa M.

2008 The Sage Encyclopedia of Qualitative Research Methods: A-L. SAGE.

Goskar, Tom

2012 Wessex Archaeology and the Web: Amesbury Archer to Archaeocast. In Archaeology and Digital Communication: Towards Strategies of Public Engagement, editor Chiara Bonacchi. Archetype Publications: London, pp. 25-37.

Hardesty, Donald L. and Barbara J. Little

2009 Assessing Site Significance: A Guide for Archaeologists and Historians.

AltaMira Press: Lanham.

Henderson, A. Gwynn and Linda S. Levstik

2016 Reading Objects: Children Interpreting Material Culture. Advances in Archaeological Practice 4(4):503-516.

Internet Live Stats

2020 Total number of Websites. Electronic document, http://www.internetlivestats.com/total-number-of-websites/, accessed January 5, 2020.

Jeong, Dahn, Michael Cheng, Mireille St-Jean, and Alireza Jalali

2019 Evaluation of eMentalHealth.ca, a Canadian Mental Health Website Portal: Mixed Methods Assessment. JMIR Mental Health 6(9):1-11.

Kaur, Sukhpuneet, Kulwant Kaur, and Parminder Kaur

2016 Analysis of Website Usability Evaluation Methods. $3^{\text {rd }}$ International Conference on Computing for Sustainable Global Development:10431046.

Kelpšienè, Ingrida

2019 Exploring Archaeological Organizations' Communication on Facebook: A Review of MOLA's Facebook Page. Advances in Archaeological Practice 7(2):203-214.

King, Eleanor M.

2016 Systematizing Public Education in Archaeology. Advances in Archaeological Practice 4(4): 415-424.

Lederman, Doug

2020 The Shift to Remote Learning: The Human Element. Inside Higher Ed, https:/www.insidehighered.com/digital-learning/article/2020/03/25/howshift-remote-learning-might-affect-students-instructors-and, accessed May 23, 2020. 
Limp, W. Fredrick

2011 Web 2.0 and Beyond, or On the Web, Nobody Knows You're an Archaeologist. In Archaeology 2.0: New Approaches to Communication and Collaboration, edited by Eric C. Kansa, Sarah Whitcher Kansa, and Ethan Watrall. Cotsen Institute of Archaeology Press: Los Angeles, pp. 265-280.

Lipe, William D.

1974 A Conservation Model for Archaeology. Kiva 39(3/4): 213-245.

2002 Public Benefits of Archaeological Research. In Public Benefits of Archaeology, edited by Little, Barbara J. University Press of Florida: Gainesville, pp. 20-28.

Little, Barbara J.

2012 Public Benefits of Archaeology. In The Oxford Handbook of Public Archaeology, edited by Skeates, Robin, Carol McDavid and John Carman. Oxford University Press: Oxford, 395-413.

Little, Barbara J. and Paul A. Shackel

2014 Archaeology, Heritage, and Civic Engagement: Working toward the Public Good. Left Coast Press: Walnut Creek.

Lock, Gary

2006 Computers, Learning and Teaching in Archaeology: Life Past and Present on the Screen. In Digital Archaeology: Bridging Method and Theory, edited by Thomas L. Evans and Patrick Daly. Routledge: London, pp. 226-235.

Matsuda, Akira and Katsuyuki and Okamura, editors

2011 Introduction: New Perspectives in Global Public Archaeology. In New Perspectives in Global Public Archaeology, pp. 1-18. Springer: New York.

McDavid, Carol

2004 Towards a More Democratic Archaeology? The Internet and Public Archaeological Practice. In Public Archaeology, edited by Nick Merriman. Routledge, pp. 159-183.

2007 Beyond Strategy and Good Intentions: Archaeology, Race, and White Privilege. In Archaeology as a Tool of Civic Engagement, ed. Barbara J. Little and Paul A. Shackel, AltaMira Press: Lanham, pp.67-88.

McManamon, Francis P.

2002 Heritage, History, and Archaeological Educators. In Public Benefits of Archaeology, edited by Little, Barbara J. University Press of Florida: Gainesville, pp. 31-45. 
Moyer, Teresa S.

2015 Building Capacity for Co-Created Digital Moviemaking through Youth Programs. Advances in Archaeological Practice 3(3): 291-300.

Mullins, Paul R.

2007 Politics, Inequality, and Engaged Archaeology. In Archaeology as a Tool of Civic Engagement, ed. Barbara J. Little and Paul A. Shackel, AltaMira Press: Lanham, pp.89-108.

Neuendorf, Kimberly A.

2017 The Content Analysis Guidebook. SAGE: Los Angeles.

Pew Research Center

$202053 \%$ of Americans Say the Internet Has Been Essential During the COVID19 Outbreak. Electronic document, https://www.pewresearch.org/internet/2020/04/30/53-of-americans-saythe-internet-has-been-essential-during-the-covid-19-outbreak/, accessed May 23, 2020.

PLAIN

(n.d.) Plainlanguage.com: Improving Communication from the Federal Government to the Public. Electronic document, http://www.plainlanguage.gov/index.cfm, accessed March 19, 2015,

Rathje, W. L.

2002 Garbology: The Archaeology of Fresh Garbage. In Public Benefits of Archaeology, edited by Little, Barbara J. University Press of Florida: Gainesville, pp. 85-100.

Redish, Janice (Ginny)

2012 Letting Go of the Words. Elseviera; Amsterdam.

Reetz, Elizabeth and William Quackenbush

2016 Creating Collaborative Learning Opportunities for Indigenous Youth with Archaeology-Based Environmental Education. Advances in Archaeological Practice 4(4):492-502.

Richardson, Lorna

2013 A Digital Public Archaeology. Papers from the Institute of Archaeology 23. 2014 Understanding Archaeological Authority in a Digital Context. Internet Archaeology 38.

Richardson, Lorna-Jane and Jaime Almansa-Sánchez 2015 Do You Even Know What Public Archaeology Is? Trends, Theory, Practice, 
Ethics. World Archaeology, Electronic document, http://dx.doi.org/10.1080/00438243.2015.1017599, accessed March 23, 2015.

Rodríguez Temiño, Ignacio and Daniel González Acuña

2014 Using Facebook to Build a Community in the Conjunto Arquelógico de

Carmona (Seville, Spain). Online Journal in Public Archaeology 4:61-93.

Schreier, Margrit

2014 Qualitative Content Analysis. In The SAGE Handbook of Qualitative Data Analysis, ed. Uwe Flick, pp. 170-183.

Shackel, Paul A.

2007 Civic Engagement and Social Justice: Race on the Illinois Frontier. In Archaeology as a Tool of Civic Engagement, editors Barbara J. Little and Paul A. Shackel. AltaMira Press: Lanham, pp. 243-262.

Society for American Archaeology

2016 Public Archaeology Is... Electronic document, http://www.saa.org/publicftp/PUBLIC/forArchaeologists/outreach_PAis.h tml, accessed May 27, 2017.

Sowter, Julie, Felicity Astin, Louise Dye, Paul Marshall, and Peter Knapp

2016 Assessment of the Quality and Content of Website Health Information about Herbal Remedies for Menopausal Symptoms. Maturitas 88:16-22.

Stone, Peter

2015 Sharing Archaeology: Academe, Practice and the Public. Routledge: London.

Styliaras, Georgios

2015 Towards a Web-Based Archaeological Excavation Platform for

Smartphones: Review and Potentials. SpringerPlus 4(311).

Sun, Sunny, Davis Ka Chio Fong, Rob Law, and Shan He

2016 An Updated Comprehensive Review of Website Evaluation Studies in Hospitality and Tourism. International Journal of Contemporary Hospitality Management 29(1):355-373.

Thomas, Ben and Meredith Anderson Langlitz 2016 Archaeology Fairs and Community-Based Approaches to Heritage Education. Advances in Archaeological Practice 4(4):465-478.

Thum, Jen and Julia Troche 2016 Visitor as Researcher: Making Archaeology More Accessible with Broken 
and Unprovenienced Objects. Advances in Archaeological Practice 4(4):537-549.

Walker, Dominic

2014a Antisocial Media in Archaeology? Archaeological Dialogues 21(2): 217235.

2014b Decentering the Discipline? Archaeology, Museums and Social Media. Online Journal in Public Archaeology 1: 77-102.

Wiliam, Dylan

2010 Standardized Testing and School Accountability. Educational Psychologist 45(2): 107-122.

Wilson, Douglas C.

2015 A Mongrel Crowd of Canadians, Kanakas and Indians: The United States National Park Public Service Public Archaeology Programme and Fort Vancouver's Village. Journal of Community Archaeology \& Heritage 2(3): 221-237.

World Wide Web Consortium

2005 Web Accessibility Initiative. Electronic document, http://www.w3.org, accessed Nov. 15, 2015.

Wylie, Alison

1999 Science, Conservation, and Stewardship: Evolving Codes of Conduct in Archaeology. Science and Engineering Ethics 5: 319-336.

Yannacopoulos, Denis, Panagiotis Manolitzas, Nikolaos Matasatsinis, and Evangelos Grigoroudis

2014 Evaluating Websites and Web Services, IGI Global: Hershey.

Zimmerman, Larry

2003 Presenting the Past. AltaMira Press: Walnut Creek.

Zohre, Mohamadi

2018 Comparative Effect of Online Summative and Formative Assessment on EFL Student Writing Ability. Studies in Educational Evaluation 59: 2940 . 
Appendix A: Table of Code Frequency of Franklin and Moe Codes and Webpage Element Codes by Webpage

\begin{tabular}{|c|c|c|c|c|c|c|c|c|c|c|c|c|c|c|c|}
\hline Webpage & $\begin{array}{l}\text { Acc } \\
\text { ess }\end{array}$ & $\begin{array}{l}\text { Con } \\
\text { tent }\end{array}$ & $\begin{array}{l}\text { Fund. } \\
\text { Conc. }\end{array}$ & $\begin{array}{l}\text { Stew } \\
\text { ard. }\end{array}$ & Uses & $\begin{array}{l}\text { Theme } \\
\text { Totals }\end{array}$ & $\begin{array}{l}\text { Body } \\
\text { Text }\end{array}$ & $\begin{array}{l}\text { Cap } \\
\text { tion }\end{array}$ & $\begin{array}{l}\text { Grap } \\
\text { hic }\end{array}$ & $\begin{array}{l}\text { Head } \\
\text { line }\end{array}$ & $\begin{array}{l}\text { Link } \\
\text { Name }\end{array}$ & Photo & $\begin{array}{c}\text { Sub } \\
\text { head }\end{array}$ & Video & $\begin{array}{l}\text { Eleme } \\
\text { Total }\end{array}$ \\
\hline \multicolumn{16}{|c|}{ Amer. Journ. of Arch. } \\
\hline About & 1 & 1 & 0 & 0 & 0 & 2 & 1 & 0 & 0 & 0 & 0 & 1 & 0 & 0 & 2 \\
\hline AJA Open Access & 0 & 0 & 0 & 0 & 0 & $\mathbf{0}$ & 0 & 0 & 0 & 0 & 0 & 0 & 0 & 0 & $\mathbf{0}$ \\
\hline Archive & 2 & 0 & 1 & 0 & 0 & 3 & 1 & 0 & 1 & 0 & 0 & 1 & 0 & 0 & 3 \\
\hline Author guide & 0 & 0 & 1 & 0 & 0 & 1 & 0 & 0 & 0 & 0 & 0 & 1 & 0 & 0 & 1 \\
\hline Home & 0 & 9 & 1 & 0 & 0 & 10 & 0 & 0 & 0 & 0 & 0 & 7 & 1 & 0 & 8 \\
\hline Learning resources & 1 & 0 & 0 & 0 & 0 & 1 & 1 & 0 & 0 & 0 & 0 & 0 & 0 & 0 & 1 \\
\hline Subscribe & 2 & 0 & 1 & 0 & 0 & 3 & 0 & 0 & 2 & 0 & 0 & 2 & 0 & 0 & 4 \\
\hline Support the AJA & 0 & 0 & 1 & 0 & 0 & 1 & 1 & 0 & 0 & 0 & 0 & 0 & 0 & 0 & 1 \\
\hline \multicolumn{16}{|l|}{$\begin{array}{l}\text { Amer. Mus. of Nat. } \\
\text { Hist. }\end{array}$} \\
\hline Home & 9 & 8 & 16 & 0 & 0 & 33 & 11 & 0 & 3 & 1 & 0 & 5 & 10 & 1 & 31 \\
\hline \multicolumn{16}{|l|}{ Arch. Channel } \\
\hline Audio news & 0 & 12 & 2 & 0 & 0 & 14 & 14 & 0 & 0 & 0 & 0 & 0 & 0 & 0 & 14 \\
\hline Film festival & 1 & 0 & 2 & 0 & 1 & 4 & 2 & 0 & 1 & 0 & 0 & 1 & 0 & 1 & 5 \\
\hline Goods \& services & 7 & 1 & 7 & 0 & 1 & 16 & 6 & 0 & 4 & 0 & 0 & 2 & 2 & 0 & 14 \\
\hline Home & 0 & 5 & 5 & 1 & 1 & 12 & 5 & 0 & 1 & 2 & 0 & 3 & 0 & 0 & 11 \\
\hline Links & 4 & 17 & 5 & 5 & 1 & 32 & 21 & 0 & 0 & 0 & 10 & 0 & 0 & 0 & 31 \\
\hline Membership & 0 & 0 & 0 & 0 & 0 & $\mathbf{0}$ & 0 & 0 & 0 & 0 & 0 & 0 & 0 & 0 & $\mathbf{0}$ \\
\hline Store & 0 & 3 & 1 & 0 & 0 & 4 & 0 & 0 & 2 & 0 & 0 & 3 & 0 & 0 & 5 \\
\hline Strata & 1 & 0 & 3 & 0 & 2 & 6 & 1 & 0 & 0 & 0 & 0 & 1 & 3 & 0 & 5 \\
\hline Underwriting & 2 & 0 & 0 & 0 & 0 & 2 & 2 & 0 & 0 & 0 & 0 & 0 & 0 & 0 & 2 \\
\hline \multicolumn{16}{|l|}{ Arch. Inst. of Amer. } \\
\hline About & 11 & 3 & 7 & 8 & 4 & 33 & 8 & 1 & 1 & 1 & 6 & 7 & 1 & 0 & 25 \\
\hline Education & 11 & 0 & 9 & 4 & 0 & 24 & 8 & 0 & 2 & 1 & 2 & 7 & 2 & 0 & 22 \\
\hline Events & 5 & 4 & 2 & 0 & 0 & 11 & 1 & 0 & 1 & 0 & 3 & 3 & 4 & 0 & 12 \\
\hline
\end{tabular}




\begin{tabular}{|c|c|c|c|c|c|c|c|c|c|c|c|c|c|c|}
\hline Fieldwork & 13 & 1 & 15 & 5 & 0 & 34 & 11 & 0 & 4 & 0 & 4 & 9 & 1 & 0 \\
\hline Give & 7 & 0 & 8 & 7 & 0 & 22 & 8 & 0 & 3 & 0 & 3 & 6 & 0 & 0 \\
\hline Home & 7 & 0 & 19 & 3 & 0 & 29 & 3 & 0 & 5 & 0 & 6 & 16 & 0 & 0 \\
\hline Membership & 1 & 0 & 8 & 2 & 0 & 11 & 0 & 0 & 1 & 0 & 5 & 5 & 0 & 0 \\
\hline Professionals & 7 & 0 & 10 & 3 & 0 & 20 & 4 & 0 & 2 & 0 & 4 & 8 & 1 & 0 \\
\hline Site preservation & 3 & 2 & 7 & 17 & 0 & 29 & 10 & 0 & 1 & 5 & 6 & 5 & 0 & 0 \\
\hline \multicolumn{15}{|l|}{ Arch. Mag. } \\
\hline Home & 4 & 15 & 20 & 1 & 1 & 41 & 1 & 0 & 10 & 4 & 7 & 15 & 0 & 4 \\
\hline Magazine & 5 & 6 & 10 & 0 & 0 & 21 & 4 & 0 & 11 & 1 & 0 & 10 & 0 & 0 \\
\hline News & 4 & 21 & 8 & 0 & 4 & 37 & 20 & 0 & 5 & 7 & 0 & 4 & 0 & 0 \\
\hline Podcast & 5 & 2 & 7 & 0 & 0 & 14 & 1 & 0 & 6 & 0 & 0 & 7 & 0 & 0 \\
\hline Reader info & 0 & 0 & 0 & 0 & 0 & $\mathbf{0}$ & 0 & 0 & 0 & 0 & 0 & 0 & 0 & 0 \\
\hline Subscribe & 2 & 0 & 0 & 0 & 0 & 2 & 0 & 0 & 1 & 1 & 0 & 0 & 0 & 0 \\
\hline Travel & 0 & 0 & 1 & 0 & 0 & 1 & 0 & 0 & 1 & 0 & 0 & 1 & 0 & 0 \\
\hline Videos & 3 & 11 & 18 & 0 & 0 & 32 & 0 & 0 & 3 & 0 & 11 & 8 & 0 & 10 \\
\hline
\end{tabular}

Boston Univ.

\begin{tabular}{|c|c|c|c|c|c|c|c|c|c|c|c|c|c|c|c|}
\hline About us & 0 & 0 & 5 & 0 & 1 & 6 & 2 & 0 & 1 & 0 & 2 & 1 & 0 & 0 & 6 \\
\hline Academics & 1 & 0 & 4 & 0 & 2 & 7 & 3 & 0 & 0 & 1 & 2 & 1 & 0 & 0 & 7 \\
\hline Donate & 1 & 0 & 2 & 0 & 0 & 3 & 1 & 0 & 0 & 0 & 2 & 0 & 0 & 0 & 3 \\
\hline Get involved & 3 & 0 & 3 & 0 & 0 & 6 & 2 & 0 & 1 & 0 & 2 & 1 & 0 & 0 & 6 \\
\hline Home (archaeology) & 1 & 1 & 3 & 0 & 2 & 7 & 2 & 0 & 0 & 0 & 3 & 1 & 0 & 0 & 6 \\
\hline News \& events & 0 & 0 & 2 & 0 & 0 & 2 & 0 & 0 & 0 & 0 & 2 & 0 & 0 & 0 & 2 \\
\hline People & 0 & 0 & 1 & 0 & 0 & 1 & 0 & 0 & 0 & 0 & 1 & 0 & 0 & 0 & 1 \\
\hline Research \& fieldwork & 0 & 2 & 5 & 0 & 1 & 8 & 5 & 0 & 0 & 0 & 0 & 2 & 0 & 0 & 7 \\
\hline \multicolumn{16}{|l|}{ Carleton College } \\
\hline Courses & 0 & 7 & 8 & 0 & 2 & 17 & 13 & 0 & 0 & 3 & 0 & 0 & 0 & 0 & 16 \\
\hline Events & 0 & 2 & 1 & 0 & 0 & 3 & 0 & 0 & 0 & 0 & 3 & 0 & 0 & 0 & 3 \\
\hline Faculty \& staff & 0 & 0 & 0 & 0 & 0 & $\mathbf{0}$ & 0 & 0 & 0 & 0 & 0 & 0 & 0 & 0 & $\mathbf{0}$ \\
\hline
\end{tabular}




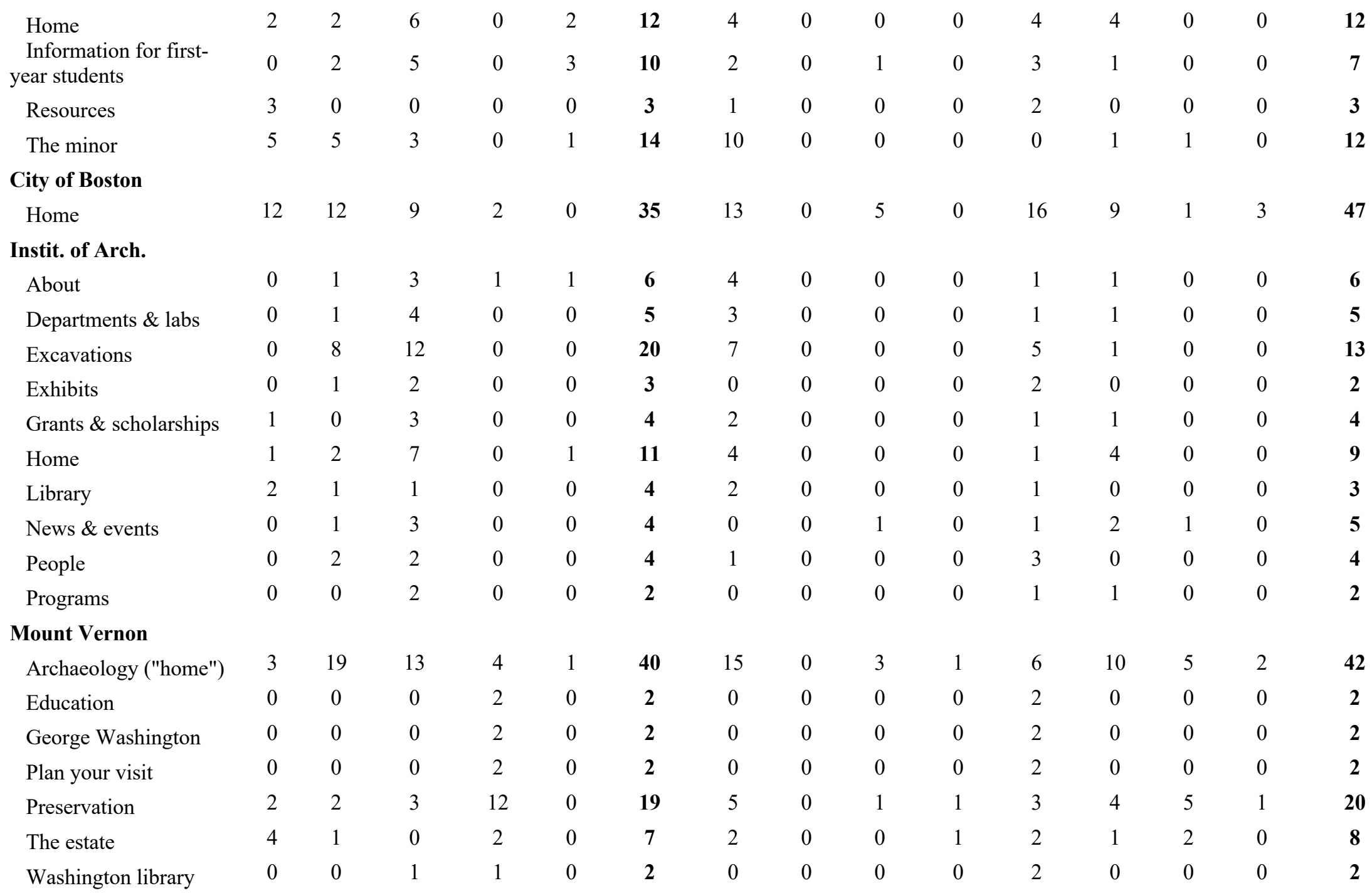

Soc. for Amer. Arch.

About the Society

For Members

0




\begin{tabular}{|c|c|c|c|c|c|c|c|c|c|c|c|c|c|c|c|}
\hline For the Press & 3 & 0 & 0 & 0 & 0 & 3 & 3 & 0 & 0 & 0 & 0 & 0 & 0 & 0 & 3 \\
\hline For the Public & 11 & 1 & 2 & 0 & 3 & 17 & 8 & 0 & 2 & 0 & 0 & 2 & 3 & 0 & 15 \\
\hline Home & 4 & 1 & 4 & 0 & 2 & 11 & 2 & 0 & 5 & 0 & 0 & 4 & 0 & 0 & 11 \\
\hline $\begin{array}{l}\text { What is Archaeology } \\
\text { (home) }\end{array}$ & 9 & 12 & 26 & 3 & 4 & 54 & 41 & 0 & 0 & 3 & 3 & 0 & 0 & 0 & 47 \\
\hline \multicolumn{16}{|l|}{ Trent Univ. } \\
\hline Contact & 0 & 0 & 0 & 0 & 0 & $\mathbf{0}$ & 0 & 0 & 0 & 0 & 0 & 0 & 0 & 0 & $\mathbf{0}$ \\
\hline Faculty \& research & 0 & 0 & 0 & 0 & 0 & $\mathbf{0}$ & 0 & 0 & 0 & 0 & 0 & 0 & 0 & 0 & $\mathbf{0}$ \\
\hline Program & 3 & 0 & 5 & 0 & 2 & 10 & 7 & 0 & 0 & 0 & 0 & 2 & 0 & 0 & 9 \\
\hline The experience & 10 & 9 & 5 & 1 & 0 & 25 & 8 & 0 & 1 & 1 & 5 & 2 & 0 & 0 & 17 \\
\hline Welcome (home) & 3 & 1 & 3 & 1 & 5 & 13 & 9 & 0 & 1 & 0 & 0 & 2 & 0 & 0 & 12 \\
\hline \multicolumn{16}{|l|}{ U. of Exeter } \\
\hline Careers & 0 & 0 & 8 & 1 & 12 & 21 & 13 & 1 & 0 & 0 & 5 & 2 & 0 & 0 & 21 \\
\hline Contact & 0 & 1 & 4 & 0 & 3 & 8 & 0 & 0 & 0 & 0 & 6 & 2 & 0 & 0 & 8 \\
\hline Entry requirements & 0 & 0 & 2 & 0 & 3 & 5 & 0 & 0 & 0 & 0 & 4 & 1 & 0 & 0 & 5 \\
\hline Fieldwork & 0 & 2 & 9 & 0 & 3 & 14 & 3 & 0 & 1 & 0 & 6 & 2 & 1 & 1 & 14 \\
\hline Learning & 1 & 0 & 8 & 0 & 3 & 12 & 4 & 0 & 1 & 0 & 5 & 2 & 0 & 0 & 12 \\
\hline Overview (home) & 2 & 4 & 7 & 0 & 8 & 21 & 11 & 0 & 0 & 0 & 7 & 2 & 0 & 0 & 20 \\
\hline Structure & 2 & 22 & 24 & 0 & 7 & 55 & 44 & 0 & 1 & 0 & 5 & 2 & 0 & 0 & 52 \\
\hline \multicolumn{16}{|l|}{ U. of Gothenburg } \\
\hline About us & 2 & 4 & 3 & 0 & 2 & 11 & 1 & 0 & 0 & 0 & 7 & 0 & 3 & 0 & 11 \\
\hline Collaboration & 1 & 0 & 0 & 0 & 0 & 1 & 1 & 0 & 0 & 0 & 0 & 0 & 0 & 0 & 1 \\
\hline Contact us & 2 & 0 & 0 & 0 & 0 & 2 & 0 & 0 & 0 & 0 & 2 & 0 & 0 & 0 & 2 \\
\hline Disciplines (home) & 0 & 1 & 1 & 0 & 0 & 2 & 1 & 0 & 0 & 0 & 0 & 0 & 0 & 0 & 1 \\
\hline Education & 0 & 0 & 0 & 0 & 0 & $\mathbf{0}$ & 0 & 0 & 0 & 0 & 0 & 0 & 0 & 0 & $\mathbf{0}$ \\
\hline Research & 1 & 17 & 7 & 0 & 1 & 26 & 20 & 0 & 0 & 0 & 0 & 0 & 1 & 0 & 21 \\
\hline \multicolumn{16}{|l|}{ U. of Oxford } \\
\hline Academic staff & 0 & 25 & 2 & 0 & 1 & 28 & 27 & 0 & 0 & 0 & 0 & 0 & 0 & 0 & 27 \\
\hline Archaeology "home" & 1 & 2 & 1 & 0 & 1 & 5 & 4 & 0 & 0 & 0 & 0 & 1 & 0 & 0 & 5 \\
\hline
\end{tabular}




\begin{tabular}{|c|c|c|c|c|c|c|c|c|c|c|c|c|c|c|c|}
\hline Archaeology website & 0 & 0 & 6 & 0 & 0 & 6 & 0 & 0 & 0 & 0 & 1 & 4 & 0 & 1 & 6 \\
\hline $\begin{array}{l}\text { Graduate study in } \\
\text { archaeology }\end{array}$ & 0 & 0 & 0 & 0 & 0 & $\mathbf{0}$ & 0 & 0 & 0 & 0 & 0 & 0 & 0 & 0 & $\mathbf{0}$ \\
\hline $\begin{array}{l}\text { Introducing our } \\
\text { courses }\end{array}$ & 0 & 0 & 0 & 0 & 0 & $\mathbf{0}$ & 0 & 0 & 0 & 0 & 0 & 0 & 0 & 0 & $\mathbf{0}$ \\
\hline $\begin{array}{l}\text { Part-time and flexible } \\
\text { study }\end{array}$ & 0 & 0 & 0 & 0 & 0 & $\mathbf{0}$ & 0 & 0 & 0 & 0 & 0 & 0 & 0 & 0 & $\mathbf{0}$ \\
\hline $\begin{array}{l}\text { Postgraduate applicant } \\
\text { privacy } \\
\text { policy }\end{array}$ & 0 & 0 & 0 & 0 & 0 & $\mathbf{0}$ & 0 & 0 & 0 & 0 & 0 & 0 & 0 & 0 & $\mathbf{0}$ \\
\hline Research & 0 & 8 & 1 & 0 & 0 & 9 & 1 & 0 & 0 & 0 & 0 & 5 & 3 & 0 & 9 \\
\hline Research courses & 0 & 0 & 0 & 0 & 0 & $\mathbf{0}$ & 0 & 0 & 0 & 0 & 0 & 0 & 0 & 0 & $\mathbf{0}$ \\
\hline $\begin{array}{l}\text { Social Sciences } \\
\text { Division }\end{array}$ & 0 & 0 & 0 & 0 & 0 & $\mathbf{0}$ & 0 & 0 & 0 & 0 & 0 & 0 & 0 & 0 & $\mathbf{0}$ \\
\hline Taught courses & 0 & 0 & 0 & 0 & 0 & $\mathbf{0}$ & 0 & 0 & 0 & 0 & 0 & 0 & 0 & 0 & $\mathbf{0}$ \\
\hline Code totals & 219 & 304 & 437 & 96 & 95 & 1151 & 469 & 2 & 96 & 34 & 202 & 220 & 51 & 24 & 1098 \\
\hline
\end{tabular}

